\title{
Newly Emergent Apelin Expressing Endothelial Stem-like Cells Orchestrate Lung Microvascular Repair
}

\author{
Rafael Soares Godoy ${ }^{1,2}$, David P Cook ${ }^{1,3}$, Nicholas D Cober ${ }^{1,2,3}$, Yupu Deng ${ }^{1,2}$, Liyuan Wang ${ }^{1,2}$, \\ Ananya Chakravarti ${ }^{1,2}$, Katelynn Rowe ${ }^{1,2}$, and Duncan J Stewart ${ }^{1,2,3,4}$ \\ ${ }^{1}$ Ottawa Hospital Research Institute, \\ ${ }^{2}$ Sinclair Centre for Regenerative Medicine Program, Ottawa, ON, Canada \\ ${ }^{3}$ University of Ottawa, Faculty of Medicine, Department of Cellular and Molecular Medicine, \\ Ottawa, ON, Canada \\ ${ }^{4}$ Correspondence to Duncan J. Stewart, MD, Ottawa Hospital Research Institute, 501 Smyth Rd, \\ Ottawa, ON, K1H 8L6, Canada. E-mail djstewart@ohri.ca
}

\section{ORCID IDs:}

RSG: 0000-0002-7094-9487

DJS: 0000-0002-9113-8691

Author contributions: RSG has contributed to all aspects of this work, from conception and performance of the experiments to data analysis and drafting of the manuscript. DPC was instrumental in the performance, analysis, and interpretation of the single-cell RNA-seq studies. NDC contributed to lung dissociation optimization, single cell study acquisition, flow cytometry acquisition and the performance and interpretation of in vivo studies. YD was involved with animal studies and with the performance and analysis of the micro-CT data. LW performed immunostaining and contributed to the analysis of the single-cell transcriptomics data and drafting of the manuscript. AC contributed to studies on inhibition of apelin signaling. KR was involved with animal studies, flow cytometry panel design, flow cytometry acquisition, data analysis and interpretation. DJS was involved in conception and design of experiments, data analysis and interpretation and drafting of the manuscript, and is accountable for all aspect of this work.

Sources of funding: This work was supported by a Foundation award from the Canadian Institutes for Health Research (FDN - 143291) to DJS.

Short title: Mapping lung EC repair by single-cell transcriptomics

Descriptor: 3.4. Endothelium

Total Word Count: 3,695

This article has an online data supplement, which is accessible from this issue's table of content online at www.atsjournals.org 


\begin{abstract}
: (253 words)
Rational: Endothelial damage plays a central role in acute lung injury, and regeneration of lung vascular endothelium is required for its resolution in preclinical models.

Objectives: We sought to define the cellular and molecular mechanisms underlying lung microvascular regeneration in acute lung injury induced by lung endothelial cell ablation.
\end{abstract}

Methods: Transgenic mice were created expressing endothelial-targeted human diphtheria toxin receptor. Changes in lung cell populations and gene expression profiles were determined using single-cell RNA sequencing of dissociated lung cells (10x Genomics) at baseline (day 0) and days 3, 5 and 7 days after lung endothelial cell ablation.

Measurements and Main Results: Intratracheal instillation of diphtheria toxin resulted in ablation of $\sim 70 \%$ of lung endothelial cells, producing severe acute lung injury, with complete resolution by 7 days. Single cell analysis revealed 8 distinct endothelial cell clusters, including type-A capillary endothelial cells which were characterized by the unique expression of apelin at baseline. Diphtheria toxin-induced ablation resulted in the emergence of novel stem-like endothelial cells in the transitional 'general' capillary type-B endothelial population at day 3, characterized by the de novo expression of apelin. This was followed by the appearance of proliferative endothelial cells at day 5 expressing apelin receptor and Forkhead box M1 which were responsible for replenishment of all depleted endothelial cell populations. Treatment with an apelin receptor antagonist prevented recovery post DT resulting in excessive mortality.

Conclusions: Targeted endothelial cell ablation revealed a remarkable regenerative capacity of the lung microvasculature orchestrated by newly emergent apelin-expressing endothelial stemlike cells primed for endothelial repair. 
Subject Terms: (5 terms - MESH terms): angiogenesis, physiological; cell, vascular endothelial; acute lung injury; pulmonary hypertension; gene, transgenic apoptosis inducing

\section{Introduction}

Damage to lung microvascular endothelial cells (ECs) is recognized as an important mechanism in acute lung injury (ALI) contributing to impairment in gas exchange which, in severe cases, leads to the adult respiratory distress syndrome (ARDS)(1). Endothelial injury results in increased alveolar capillary permeability, plasma protein leak and influx of inflammatory cells into airspaces (2-4). Recent experience with SARS-CoV2 related ARDS has highlighted the importance of the endothelium as a target for COVID-19-induced lung injury, producing severe endothelialitis and necrosis $(5,6)$ contributing to marked impairment in gas exchange, extreme inflammation.

Recently, EC repair and microvascular regeneration has been proposed as a novel therapeutic strategy for the treatment of $\operatorname{ARDS}(7,8)$; however, little is known about the endogenous mechanisms underlying lung microvasculature regeneration. In experimental models, Forkhead box M1 (FoxM1), a member of the fox family of transcriptional factors (9), has been shown to promote microvascular EC regeneration and resolution of lung injury $(10,11)$. FoxM1 expression is upregulated in ECs during the repair phase after lung injury and vascular repair is markedly impaired in transgenic mice with endothelial-targeted FoxM1 deficiency (12) while overexpression of FoxM1 targeted to ECs enhanced lung microvascular regeneration (13). As well, apelin, which is an endogenous endothelial-derived agonist of the G-protein coupled APJ receptor, plays central role in angiogenesis and vascular development in numerous organs (14, 
15), and has also been implicated in the maintenance and restoration of lung microvascular structure and function in ALI and $\operatorname{ARDS}(13,16,17)$.

We now report on a novel model of ALI induced by targeted lung EC ablation after intratracheal delivery of diphtheria toxin (DT) in transgenic mice harboring the human DT receptor (DTR) restricted to the vascular endothelium. DT administration resulted in loss of $\sim 70 \%$ of lung ECs with near complete recovery by 1 week, providing a unique opportunity to define the mechanisms underlying EC regeneration and lung microvascular repair using serial single-cell transcriptomic analysis. By single-cell RNA sequencing (scRNA-seq), two specialized lung microvascular EC populations have previously been characterized in the normal lung (18); specifically, 'aerocytes' (aCap ECs), which contributed to the air-blood barrier and expressed apelin, and general (gCap) ECs expressing the apelin receptor involved in microvascular repair. In the DT model of ALI, we now describe the emergence of a novel, stem-like population of ECs at 3 days post injury, appearing within a transitional gCap cluster, and exhibiting de novo expression of apelin together with vascular endothelial stem cell markers. This was rapidly followed by the emergence within the same cluster of apelin receptor expressing, FoxM1positive, proliferative ECs responsible for repopulating all depleted lung endothelial fields.

\section{Material and Methods}

Transgenic models: All animal procedures were approved by the University of Ottawa Animal Care Ethics Committee in agreement with guidelines from the Canadian Council for the Care of Laboratory Animals. Transgenic animals were obtained from Jackson's Laboratories including mice with Cre-inducible DTR flanked by loxP sites (C57BL/6-Gt(ROSA)26Sor ${ }^{\text {tml(HBEGF)Awai/J) }}$ and expressing Cre-recombinase under the endothelial cell (EC) restricted promoter, VE- 
cadherin (Cdh5) (B6.FVB-Tg(Cdh5-cre)7Mlia/J) (Stock numbers: 007900 and 006137, respectively). Stocks were maintained by crossing homozygous animals. Binary transgenic animals harboring Cdh5-cre-iDTR were obtained by crossing homozygous DTR and Cdh5 mice to generate double heterozygous offspring (Figure 1A). Only male animals 10-12 weeks of age were used for experiments in this manuscript, unless otherwise specified. All animals were genotyped using primer sequences provided by Jackson's Laboratory.

Diphtheria Toxin Administration: Stocks of Diphtheria toxin from Corynebacterium diphtheriae (Sigma-Aldrich, Oakville, ON, Canada) were prepared (1 mg/mL) in sterile distilled water and stored in single use aliquots at $-20^{\circ} \mathrm{C}$. Animals were anaesthetized with ketamine (100 $\mathrm{mg} / \mathrm{Kg}$ i.p.) and xylazine (10 mg/Kg i.p.) and DT was delivered by intra-tracheal instillation (10 ng in $50 \mu \mathrm{Ls}$ unless otherwise specified) with a $1 \mathrm{~mL}$ syringe and measured with a micropipette. Prior to toxin administration, a water droplet was used to indicate proper positioning of the catheter into the orotracheal cavity and deemed successful by the movement of the droplet with the breathing of animals. Control animals received $50 \mu \mathrm{Ls}$ of $0.9 \%$ sterile saline.

Single-Cell RNA Sequencing Analysis: Barcoding of individual biological samples was performed using MULTI-seq, as described by McGinnis et.al.(2019) (19). RNA library construction with 10x-Genomics Single Cell 3' RNA sequencing kit v3 was processed as previously described (20). Libraries for a total of 48,347 cells were sequenced using a NextSeq500 (Illumina) with a mean depth of 8,550 reads per cell, and a median of 1,560 UMIs and 845 genes per cell. CellRanger v.4.0 software (10x Genomics) was used to process raw sequencing reads with the mm10 reference transcriptome and with additional manual annotation 
of the diphtheria toxin receptor transgene. MULTI-seq barcode libraries were further trimmed to 28bp using Trimmomatic v.0.39 (https://github.com/timflutre/trimmomatic). Further details are provided in the Online Methods.

Apelin inhibition: The role of apelin pathway in lung microvascular repair was assessed using a selective apelin receptor antagonist, ML221 (Tocris, 10mg/kg) (21) dissolved in DMSO delivered by intraperitoneal injection as previously described (22).

\section{Statistical analysis:}

Statistical analysis was performed using Prism v.8.4.2 (GraphPad Software). Results are expressed and means \pm SEM. The sample size per condition and specific statistical tests used are presented in the figure legends. Statistical analysis for the scRNA-seq data was performed according to the recommendations of analytic packages that were used as specified in the Results section and figure legends. Unless otherwise indicated, comparison between two groups was conducted with unpaired two-tail parametric t-test with a Homl-Sidak correction for multiple comparisons.

\section{Results}

Selective lung EC ablation in Cdh5-DTR mice: To target EC ablation to the lung, we administered DT via IT instillation (Figure 1A). Single administration of DT at a dose below 25ng was associated with full survival over 7 days in all animals (Figure 1B) and resulted in modest increases in right ventricular systolic pressures (RVSP) that were maximal at 10ng of DT (Figure 1C). All further studies used the 10ng dose unless otherwise specified. DTR expression was localized to lung ECs in Cdn5-DTR animals by fluorescence immunostaining (Figure 1D) 
and widespread EC apoptosis was seen at 3 days post DT administration in Cdh5-DTR mice (Figure 1E). Indeed, DT administration resulted in a profound reduction in EC numbers at 3 days by flow cytometry whether labelled for CD144 (70 $\pm 11, \mathrm{p}<0.001)$; CD31 $(70 \pm 12.2 \%$; $<<0.001)$ or CD34 (66 $\pm 26.3 \%$; p<0.001) (Figure 1F and G). Interestingly, the lung EC population fully returned to control levels by day 7 (Figure 1G).

Lung EC ablation induces an acute lung injury phenotype: Evans blue staining of the lung was increased by over 6-fold $(\mathrm{p}<0.01)$ at 3 days post DT administration, indicative of increased vascular leak (Figure 2A and B) returning to normal by 7 days. DT-induced vascular leak was restricted to the lungs with no evidence of increased vascular permeability in the heart (Figure 2B), or the liver, spleen, brain and kidneys (Figure S1). DT-treated Cdh5-DTR mice also showed histological changes at 3 days consistent with severe acute lung injury resulting in a marked increase in the lung injury score (Figure 2C and D) which was associated with the influx of CD11b/Lye6 positive neutrophils by flow cytometry but no overall change in the total number of CD45 positive cells (Figure 2E and F). Elevation in RVSP was observed as early as 48h post DT, peaking at 3 days and fully recovered to baseline levels by day 7 (Figure 2G); however, hypertrophy of the right ventricle (RV), assessed by increase in RV/LV+septal weight, was observed only at 7 days likely as a delayed consequence of RV overload. IT delivery of DT had no effect on systemic blood pressure at 3 days (Figure 2H), nor did it affect RVSP in single transgenic animals lacking the human receptor for DT (Figure 2I). High-resolution micro-CT was performed at 3,5 and 7 days post DT showing no change total arterial volume after DT administration (Figure S2), consistent with vascular injury in this model being largely localized to the alveolar capillary bed. 


\section{Changes in global lung cell populations with single cell transcriptomic profiling:}

Multiplexed scRNA-seq analysis was performed on lung tissues of Cdn5-DTR mice at day 0 (baseline) and 3, 5 and 7 days post DT administration (Figure 3A). Sample barcodes corresponding to all 12 samples were detected and included in the analysis (Figure S3A), and cells lacking a barcode, or positive for multiple barcodes, were excluded from further analysis. Cells with a high proportion ( $>30 \%)$ of mitochondrial transcripts and those with low complexity ( $<200$ detected genes) were removed from the analysis, and an additional round of doublet detection was performed to remove doublets that may have been missed during demultiplexing (eg. intrasample doublets; Figure S3B and C). A total of 21,665 cells were used for downstream analyses.

Uniform Manifold Approximation and Projection (UMAP) dimensionality reduction mapsembedding of the data revealed 21 different cell populations in the mouse lung, representing immune, endothelial, stromal and epithelial cells (Figure 3B). Cell clusters were characterized using an automated annotation tool (23) by cross referencing differential gene expression of individual clusters to previously characterized lung cells of the Tabula Muris cell atlas (Figure S4) (24). The identity of the various lung cell clusters was further confirmed by the assessment of expression of cell-specific genes in the 21 clusters (Figure S4). After DT there was a marked reduction in endothelial cells, type 2 epithelial cells and alveolar macrophage populations peaking at 5 days, with an increase in neutrophils and monocytes at 3 and 5 days, respectively, all largely recovering by day 7 (Figure 3). The cell types that were most affected by DT treatment were identified using Augur, which quantifies the extent of each cell type's 
response to experimental conditions (25). The cell types with the most extensive response included endothelial cells (clusters 11 and 0), monocytes (cluster 4), alveolar macrophages (cluster 5) and type 2 epithelial cells (cluster 10) (Figure 3D).

Changes in EC populations in response to injury: Re-clustering of the EC populations yielded 8 distinct clusters (Figure 4A), including the two distinct capillary populations: alveolar capillary type-B ECs (cluster 0) and type-A (cluster 2); pulmonary arterial (cluster 4) and venous ECs (cluster 5); as well, several 'novel' capillary EC populations (i.e. clusters 1, 3, 6 and 7). All but one of these clusters were represented at baseline (day 0) (Figure 4B), whereas cluster 7 was transient and mainly present only at 5 days after EC injury. Cluster 1 was unique in that it was a 'transitional' cluster made up of 4 distinct 'zones' each specific to a single time point before and after EC ablation. As expected, most EC populations exhibited a marked decline in cell numbers (Figure 4C), with the exception of the transitional/transient clusters 1 and 7, which showed stable or increased cell numbers, respectively. Interestingly, RNA velocity analysis (Figure 4D), which infers time-dependent changes in gene expression profiles, showed strong velocity vectors leading from cluster 2 to zone 2 of cluster 1 , and from cluster 7 towards cluster 0 . This suggests that EC clusters 1, 2 and 7 may contribute importantly to lung microvascular repair.

Mapping specialized EC populations during injury and repair: We used the top five genes that were previously reported to differentiate between two specialized alveolar capillary EC population, aerocytes (aCap) and 'general' (gCap) ECs $(18,26)$ to map these populations to the novel transitional fields that emerged after EC injury. At baseline, Car4, Endrb, Fibin and Tbx2 were localized solely to capillary type-A ECs (cluster 2) (Figure 5A-D) consistent with their 
identity as aCap ECs; whereas gGap genes, including Gpihbp1, Plvap, CD93 and Ptprb, were seen in all other clusters, including capillary type-B ECs (cluster 0), arterial (cluster 4) and venous (cluster 5) ECs.. With the possible exception of Car4, aCap genes were not found at all in the transitional/transient EC fields of cluster 1 or cluster 7 at any time post injury, while gGap genes were strongly expressed in all these regions during endothelial regeneration (Figure 5E-H). This is consistent with gCap (but not aCap) ECs playing a direct role in microvascular EC repair, as previously reported by Gillich et al (18).

Temporal sequence of angiogenic gene expression: We next characterized the temporal profile of expression of genes known to play a key role in angiogenesis and vascular repair in order to better understand the molecular basis of EC regeneration. At baseline, apelin was found to be uniquely expressed in aCap ECs of cluster 2 (Figure 6A). Other angiogenic genes, notably $K d r$ and $C D 34, N p l 1$ (neuropilin 1) and $P d g f b$ (platelet derived growth factor B), were also predominately expressed in this field at baseline (Figure 6B and C, Figure S6B and C). Interestingly, these are all markers of endothelial tip cells that play a critical role in the initiating of sprouting angiogenesis $(27,28)$. Three days after EC injury apelin expression appeared de novo in zone 2, which like all other zones of cluster 1 were clearly gCap ECs based on the expression of typical genes as shown in Figure 5. These ECs also exhibited the unique expression of Procr (protein C receptor) and Angpt2 (angiopoietin 2) (Figure 6D and Figure S6A). Importantly, Procr has recently been reported to be a marker of resident vascular endothelial stem cells (29) and whereas Angpt2 plays a role in the early stages of angiogenesis (30). 
Interestingly, zone 2 ECs did not express the apelin receptor (Aplnr) despite the expression of all other gCap markers (Figure 6E). In contrast, apelin receptor (Aplnr) expression was seen in all other gCap ECs at baseline and after EC injury. At 5 days post DT injury, Aplnr expression was present in zone 3 of cluster 1 and in cluster 7, (Figure 6E) together with the stalk cell markers, Flt1 and Notch1 and Heyl (Figure 6F, Figure S6D and E). Stalk cells are responsible for EC proliferation during sprouting angiogenesis $(27,28)$ and indeed, Ki67, a marker of cell proliferation, was seen only at day 5 , restricted to cluster 7 and zone 3 of cluster 1 , together with expression of FoxM1, a pro-proliferative transcription factor (Figure 6G-H).

Differential gene expression (DGE) profiles at baseline and after EC injury: At baseline, the top differentially expressed genes between capillary type-B ECs (cluster 0 ) and other microvascular ECs populations in healthy lungs are presented in Table 1. The gene expression profile of ECs in zone 1 of cluster 1 (the only zone present in the uninjured lung) was very similar to cluster 0 , consistent with a similar identity between these gCap EC populations, with Emp2 being one of only three differentially expressed genes the default settings of Seurat. Similarly, cluster 3, exhibited only seven genes that were differentially expressed, which intriguingly largely represented immediate early response genes, including Erg1, Junb, Fos, Ier2 and Ier3, whereas cluster 6 showed 21 differentially expressed genes, mainly involved in cytoprotection and homeostasis including Gpx3, Aldhlal and Inmt (detoxification), Gsn and Lgals1 (regulation of survival/proliferation). In contrast, EC cluster 2 was very distinct, exhibiting 45 differentially expressed genes, including the typical aCap genes as well as a number of endothelial tip-cell markers. Finally, cluster 7, which was present mainly at day 5 post injury, exhibited a predominance of genes associated with cell proliferation such as Top2a, 
Mki67, Birc5, Cenpf and Cdca8. Figure 7 shows the DGE profiles between the four zones of the transitional cluster 1, spanning the four distinct phases of microvascular regeneration and repair after EC ablation. Apelin was highly expressed in zone 2, along with Procr and Angpt2, as well as a number of genes involves in angiogenesis and EC-matrix interactions including Cyr61 (Cysteine-Rich, Angiogenic Inducer, 61), Ecm1 (Extracellular Matrix Protein 1) and Emp2 (Epithelial Membrane Protein 2). In contrast, genes that were highly expressed in zone 3 were largely related to cell proliferation and survival, notably Ki67, Birc5 (Survivin) and Cdca8 (Cell Division Cycle Associated 8), with a DEG profile similar to that of cluster 7 (Table 1).

\section{Impairment in the apelin pathway aggravates the DT-induced lung injury phenotype: An}

analysis of a publicly available dataset of young vs. aged mice (31) revealed a significant reduction in lung apelin expression in older animals (Figure 8A) which was confirmed in the Cdhr5-DTR double transgenic mice by qcRT-PCR (Figure 8B). Interestingly, aging reduced survival post DT-induced injury with only $24 \%$ of 52 week-old Cdhr5-DTR mice surviving to day 7 post DT compared to $100 \%$ survival for 12 week-old mice $(\mathrm{p}<0.01)$ (Figure $8 \mathrm{C})$.

Moreover, when young Cdhr5-DTR mice were treated with an apelin receptor antagonist, ML221, all mice succumbed to DT-induced acute lung injury by 5 days, consistent with a failure of lung microvascular repair.

\section{Discussion:}

The robust ALI phenotype induced by lung EC ablation in the Cdh5-hDTR binary transgenic mouse model is consistent with a central role for alveolar EC injury in the pathogenesis of ARDS. The DT lung injury model also provides a clear demonstration of the remarkable 
regenerative capacity of the murine lung microvasculature. Within seven days of ablation of more than $70 \%$ of the total lung EC population, there was a near complete recovery both in terms of the cell numbers and the lung injury phenotype. Therefore, the rapid endothelial regeneration and microvascular repair seen in this model affords a unique opportunity to examine the cellular and molecular mechanisms underlying such efficient microvascular repair.

Single-cell transcriptomics analysis resulted in the discrimination of eight distinct endothelial subtypes. The largest was classified as alveolar capillary type-B ECs, which was also the population which was depleted to the greatest extent following DT-induced EC ablation. Other clusters were also seen with expression profiles consistent with arterial and venous ECs. Of particular interest, was the alveolar capillary EC-type A cluster, which was the only EC population exhibiting expression of apelin in healthy lungs. These findings are in agreement with recent reports that have identified specialized EC populations in the alveolar capillary bed using single-cell analysis $(18,26,32)$. Gillich et al. identified two specialized alveolar EC populations in healthy lungs; the first expressed apelin and was termed 'aerocytes' or aCap ECs, corresponding to the capillary type-A ECs of the Tabula Muris classification (cluster 2, Figure 4A), whereas 'general' or gCap ECs expressed the apelin receptor (18), corresponding the capillary type-B ECs (cluster 0). aCap ECs were characterized as large, highly specialized cells making up the air-blood barrier and thereby playing an important structural role in gas exchange (Figure 9)(18). This population also appears to be analogous to an EC population described earlier which is in close apposition to alveolar type 1 epithelial cells and expresses high levels of Car4 $(26,32)$, one of five genes characteristic of aCap ECs (18). In contrast, gCap ECs appear to be smaller and less specialized and were located in thicker regions of the alveolar wall (18). With 
the exception of capillary type-A ECs of cluster 2, which express typical aCap genes, all other EC cell clusters seen at baseline in the healthy lung exhibited high expression of gCap-related genes (Figure 5), including arterial and venous ECs, which is consistent with the relatively generalized nature of this population.

This is the first report to describe serial changes in lung cell populations after EC injury. DT instillation triggered dynamic shifts in endothelial gene expression resulting in the emergence of a number of novel transitional and transient EC fields which have not previously been reported. In particular, EC cluster 1 was made up of 4 discreet zones, each specific to a single timepoint prior to and following EC injury. Zone 2 emerged at day 3 after EC injury and remarkably it was characterized by the de novo expression of apelin; however, this field was quite distinct from apelin expressing, aCap ECs of cluster 2 since, like all other zones of cluster 1, it exhibited a gene expression profile that was characteristic for gCap ECs (Figure 5). Zone 2 was also characterized by the exclusive expression of two genes, Procr (protein C receptor) and Angpt2 (angiopoietin 2), that have both been implicated in angiogenesis and vascular repair. Angiopoietin 2 is an endogenous antagonist of the Tie 2 receptor, and is instrumental in the initiation of angiogenic response (30), whereas Procr has recently been reported to be a marker identifying resident vascular endothelial stem cells (29). The stem/progenitor cell identity of this transitional EC field is further supported by the robust expression of CD34 (Figure 6C), which is a marker for haematopoietic stem cells (33), endothelial progenitor cells, (34) as well as angiogenic endothelial tip cells (35). 
Whereas stem-like, apelin-positive ECs showed no evidence of proliferation at day 3, they transitioned to a proliferative phenotype by day 5 as evidenced in zone 3 of cluster 1, with a gene expression profile that mirrored that of cluster 7. Both these EC populations expressed the apelin receptor as well as endothelial stalk-cell markers (Figure S6D and E), and while these transitional fields were characterized by a similar proliferative gene expression profile, cluster 7 exhibited a higher density of proliferating ECs as evidenced by FoxM1 and Mi67 expression (Figure 6G and H). As well, RNA velocity analysis suggested that ECs in cluster 7 contributed importantly to replenishment of depleted type-B ECs (cluster 0), whereas ECs in zone 3 of cluster 1 may be involved in the regeneration of arterial and venous EC populations. These findings are consistent with a role for dynamic apelin expression after endothelial injury in specifying the transition to proliferative ECs leading to lung microvascular endothelial replenishment and repair (Figure 9). Indeed, impairment of the apelin system in aged mice or inhibition of its receptor using selective antagonist resulted in failure of resolution of ALI after DT-induced lung injury and excessive mortality.

Thus, for the first time we have mapped the cellular and molecular processes involved in rapid and complete microvascular regeneration using a new model of ALI induced by targeted EC ablation. Single-cell transcriptomic analysis has revealed a novel and transient population of apelin-positive, stem-like ECs emerging soon after endothelial injury, presaging their transition into FoxM1-positive proliferating ECs expressing the apelin receptor, that were largely responsible for expansion of the EC pool and the replenishment of depleted arterial, venous and capillary ECs in this model. These findings provide new insights into the mechanisms underlying 
lung microvascular repair that could guide the development of novel strategies for the treatment of ALI and ARDS.

\section{Acknowledgments:}

Would like to thank Dr. Saad Khan, Dr. Maria Hurskainen and Dr. Ivana Mizikova for procedural guidance and advice and to Dr. Bernard Thébaud for his advice on the manuscript. This work was supported by a Foundation grant for the Canadian Institutes for Health Research to DJS (FDN - 143291).

\section{References:}

1. Ranieri VM, Rubenfeld GD, Thompson BT, Ferguson ND, Caldwell E, Fan E, Camporota L, Slutsky AS. Acute respiratory distress syndrome: the Berlin Definition. JAMA 2012;307:2526-2533.

2. Austin GE, Ratliff NB, Hollman J, Tabei S, Phillips DF. Intimal proliferation of smooth muscle cells as an explanation for recurrent coronary artery stenosis after percutaneous transluminal coronary angioplasty. Journal of the American College of Cardiology 1985;6:369.

3. Mc Fadden EP, Bauters C, Lablanche JM, Quandalle P, Leroy F, Bertrand ME. Response of human coronary arteries to serotonin after injury by coronary angioplasty. Circulation 1993;88:2076-2085.

4. Schwartz RS, Holmes DR, Topol EJ. The restenosis paradigm revisited: An alternative proposal for cellular mechanisms. Journal of the American College of Cardiology 1992;20:1284-1293.

5. Ackermann M, Verleden SE, Kuehnel M, Haverich A, Welte T, Laenger F, Vanstapel A, Werlein C, Stark H, Tzankov A, Li WW, Li VW, Mentzer SJ, Jonigk D. Pulmonary Vascular Endothelialitis, Thrombosis, and Angiogenesis in Covid-19. N Engl J Med 2020;383:120-128.

6. Jin Y, Ji W, Yang H, Chen S, Zhang W, Duan G. Endothelial activation and dysfunction in COVID-19: from basic mechanisms to potential therapeutic approaches. Signal Transduction and Targeted Therapy 2020;1-13.doi:10.1038/s41392-020-00454-7.

7. Zhao YD, Huang X, Yi F, Dai Z, Qian Z, Tiruppathi C, Tran K, Zhao Y-Y. Endothelial FoxM1 Mediates Bone Marrow Progenitor Cell-Induced Vascular Repair and Resolution of Inflammation following Inflammatory Lung Injury. Stem Cells 2014;32:1855-1864.

8. Minamino T, Komuro I. Regeneration of the endothelium as a novel therapeutic strategy 
for acute lung injury. J Clin Invest 2006;116:2316-2319.

9. $\quad$ Costa RH. FoxM1 dances with mitosis. Nature Cell Biology 2005;7:108-110.

10. Huang X, Dai Z, Cai L, Sun K, Cho J, Albertine KH, Malik AB, Schraufnagel DE, Zhao

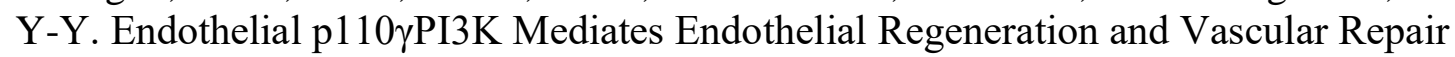
After Inflammatory Vascular Injury. Circulation 2016;133:1093-1103.

11. Bolte C, Flood HM, Ren X, Jagannathan S, Barski A, Kalin TV, Kalinichenko VV. FOXF1 transcription factor promotes lung regeneration after partial pneumonectomy. Scientific Reports 2017;1-14.doi:10.1038/s41598-017-11175-3.

12. Mirza MK, Sun Y, Zhao YD, S K Potula H-H, Frey RS, Vogel SM, Malik AB, Zhao Y-Y. FoxM1 regulates re-annealing of endothelial adherens junctions through transcriptional control of $\beta$-catenin expression. J Exp Med 2010;207:1675-1685.

13. Huang X, Zhao Y-Y. Transgenic Expression of FoxM1 Promotes Endothelial Repair following Lung Injury Induced by Polymicrobial Sepsis in Mice. In: Addison CL, editor. PLoS ONE 2012;7:e50094-8.

14. Yan J, Wang A, Cao J, Chen L. Apelin/APJ system: an emerging therapeutic target for respiratory diseases. Cellular and Molecular Life Sciences 2020;112.doi:10.1007/s00018-020-03461-7.

15. Zhang H, Chen S, Zeng M, Lin D, Wang Y, Wen X, Xu C, Yang L, Fan X, Gong Y, Zhang H, Kong X. Apelin-13 Administration Protects Against LPS-Induced Acute Lung Injury by Inhibiting NF-кB Pathway and NLRP3 Inflammasome Activation. Cell Physiol Biochem 2018;49:1918-1932.

16. Kidoya H, Takakura N. Biology of the apelin-APJ axis in vascular formation. Journal of Biochemistry 2012;152:125-131.

17. Tian X, Pu WT, Zhou B. Cellular Origin and Developmental Program of Coronary Angiogenesis. Circulation Research 2015;116:515-530.

18. Gillich A, Zhang F, Farmer CG, Travaglini KJ, Tan SY, Gu M, Bin Zhou, Feinstein JA, Krasnow MA, Metzger RJ. Capillary cell-type specialization in the alveolus. Nature 2020;1-29.doi:10.1038/s41586-020-2822-7.

19. McGinnis CS, Patterson DM, Winkler J, Conrad DN, Hein MY, Srivastava V, Hu JL, Murrow LM, Weissman JS, Werb Z, Chow ED, Gartner ZJ. MULTI-seq: sample multiplexing for single-cell RNA sequencing using lipid-tagged indices. Nature Methods 2019;1-14.doi:10.1038/s41592-019-0433-8.

20. Cook DP, Vanderhyden BC. Context specificity of the EMT transcriptional response. Nature Communications 2020;1-9.doi:10.1038/s41467-020-16066-2.

21. Maloney PR, Khan P, Hedrick M, Gosalia P, Milewski M, Li L, Roth GP, Sergienko E, Suyama E, Sugarman E, Nguyen K, Mehta A, Vasile S, Su Y, Stonich D, Nguyen H, Zeng F-Y, Novo AM, Vicchiarelli M, Diwan J, Chung TDY, Smith LH, Pinkerton AB. Discovery of 4-oxo-6-((pyrimidin-2-ylthio)methyl)-4H-pyran-3-yl 4-nitrobenzoate (ML221) as a functional antagonist of the apelin (APJ) receptor. Bioorg Med Chem Lett 2012;22:6656-6660.

22. Ishimaru Y, Shibagaki F, Yamamuro A, Yoshioka Y, Maeda S. An apelin receptor antagonist prevents pathological retinal angiogenesis with ischemic retinopathy in mice. Scientific Reports 2017;7:15062.

23. Tan Y, Cahan P. SingleCellNet: A Computational Tool to Classify Single Cell RNA-Seq Data Across Platforms and Across Species. Cell Systems 2019;9:207-213.e2.

24. Schaum N, Karkanias J, Neff NF, May AP, Quake SR, Wyss-Coray T, Darmanis S, 
Batson J, Botvinnik O, Chen MB, Chen S, Green F, Jones RC, Maynard A, Penland L, Pisco AO, Sit RV, Stanley GM, Webber JT, Zanini F, Baghel AS, Bakerman I, Bansal I, Berdnik D, Bilen B, Brownfield D, Cain C, Chen MB, Chen S, et al. Single-cell transcriptomics of 20 mouse organs creates a Tabula Muris. Nature 2018;125.doi:10.1038/s41586-018-0590-4.

25. Skinnider MA, Squair JW, Kathe C, Anderson MA, Gautier M, Matson KJE, Milano M, Hutson TH, Barraud Q, Phillips AA, Foster LJ, La Manno G, Levine AJ, Courtine G. Cell type prioritization in single-cell data. 2019;570:332-33.

26. Niethamer TK, Stabler CT, Leach JP, Zepp JA, Morley MP, Babu A, Zhou S, Morrisey EE. Defining the role of pulmonary endothelial cell heterogeneity in the response to acute lung injury. Elife 2020;9:.

27. Blanco R, Gerhardt H. VEGF and Notch in tip and stalk cell selection. Cold Spring Harb Perspect Med 2013;3:a006569.

28. Zecchin A, Kalucka J, Dubois C, Carmeliet P. How Endothelial Cells Adapt Their Metabolism to Form Vessels in Tumors. Front Immunol 2017;8:1750.

29. Yu QC, Song W, Wang D, Zeng YA. Identification of blood vascular endothelial stem cells by the expression of protein C receptor. Cell Res 2016;26:1079-1098.

30. Maisonpierre PC, Suri C, Jones PF, Bartunkova S, Wiegand SJ, Radziejewski C, Compton D, McClain J, Aldrich TH, Papadopoulos N, Daly TJ, Davis S, Sato TN, Yancopoulos GD. Angiopoietin-2, a Natural Antagonist for Tie2 That Disrupts in vivo Angiogenesis. Science 1997;277:55-60.

31. Angelidis I, Simon LM, Fernandez IE, Strunz M, Mayr CH, Greiffo FR, Tsitsiridis G, Ansari M, Graf E, Strom T-M, Nagendran M, Desai T, Eickelberg O, Mann M, Theis FJ, Schiller HB. An atlas of the aging lung mapped by single cell transcriptomics and deep tissue proteomics. Nature Communications 2019;10:963.

32. Ellis LV, Cain MP, Hutchison V, Flodby P, Crandall ED, Borok Z, Bin Zhou, Ostrin EJ, Wythe JD, Chen J. Epithelial Vegfa Specifies a Distinct Endothelial Population in the Mouse Lung. Developmental Cell 2020;52:617-630.e6.

33. Ng AP, Alexander WS. Haematopoietic stem cells: past, present and future. Cell Death Discov 2017;3:17002-4.

34. Barber CL, Iruela-Arispe ML. The ever-elusive endothelial progenitor cell: identities, functions and clinical implications. Pediatr Res 2006;59:26R-32R.

35. Siemerink MJ, Klaassen I, Vogels IMC, Griffioen AW, Van Noorden CJF, Schlingemann RO. CD34 marks angiogenic tip cells in human vascular endothelial cell cultures. Angiogenesis 2012;15:151-163.

\section{Figure Legends:}

Figure 1. Establishment of the DT-induced EC ablation model: Transgenic mice harboring Cre recombinase cDNA downstream from a 2.5-kb fragment of the VE-Cadherin (Cdh5) mouse promoter (B6.FVB-Tg(Cdhn5-cre)7Milia) were crossed with mice with Cre-inducible expression of DTR (C57BL/6-Gt(ROSA)26Sor ${ }^{\mathrm{tm} 1(\mathrm{HBEGF}) A w a i / J)}$ giving rise to Cdhn5-DTR binary transgenic 
mice (A). Single intratracheal (IT) administration of DT at doses below 20ng were compatible with survival to 7 days post treatment (B) and resulted in a dose-dependent increase in right ventricular systolic pressure (RVSP) (DT 0.1ng-18ng) (C). Immunostaining for human DTR (red) was associated with ECs (anti-CD144, green) in lung sections from Cdhn5-DTR binary transgenic mice 3 days post IT delivery of saline or DT (10ng) with DAPI nuclear staining (blue) (D). Immunostaining for activated caspase 3 (aCasp-3, red) in lung sections from binary transgenic mice 3 or 7 days after treatment DT or saline (DAPI nuclear staining in blue) (E). Representative plots of lung EC numbers assessed by flow cytometry (CD144) in binary transgenic mice 3 days after IT delivery of saline or DT (F). Summary flow cytometric data showing the percent of total lung cells staining positive using CD144, CD31 or CD34 antibodies in DT treated binary transgenic mice 3 or 7 days post treatment (dpt) compared with saline $(\mathrm{G})$. $*=\mathrm{p}<0.05 ; * *=\mathrm{p}<0.01 ; * * *=\mathrm{p}<0.005$

Figure 2, DT administration results in an acute lung injury phenotype. Representative examples of Evans blue staining of lungs from binary transgenic mice (A). Summary data showing marked increase Evans Blue lung content in binary transgenic mice treated with DT (10ng) or saline at 3 and 7 days post treatment (dpt) (B). Representative histological lung sections (H\&E staining) from binary transgenic mice at 3 and 7 days post IT administration of DT or saline (C) with the corresponding summary data for a validated lung injury score (D). Representative examples of flow cytometry plots showing gating strategy for assessing CD11b/Ly6G positive leukocytes in lungs from binary transgenic mice 3 days after IT delivery of DT or saline (E) with summary data at 3 and 7 days post treatment (dpt) (F). Time course of the effect of a single dose of DT (10 ng) or saline on right ventricular systolic pressure (RVSP) 
and the effect of DT or saline on right ventricular hypertrophy (RVH) assessed by the ratio of right ventricular plus septal/left ventricular $(\mathrm{RV}+\mathrm{S} / \mathrm{LV})$ weight at 3 and 7 days post treatment (dpt) (G). Lack of effect of DT (10ng) on systemic arterial and diastolic pressure in binary transgenic mice $(\mathrm{H})$ and on RVSP in single transgenic DTR control mice (I). An unpaired multiple t-test with Holm-Sidak multiple comparisons method with alpha (0.05) was used for analysis of data presented in panels B, D, F- I, whereas an unpaired t-test was conducted for panels C-E. $*=\mathrm{p}<0.05 ; * *=\mathrm{p}<0.01 ; * * *=\mathrm{p}<0.005$

\section{Figure 3. Multiplexed single cell transcriptomic analysis after DT-induced lung EC}

ablation: Schematic of workflow showing the experimental design (A). Three separate cohorts (3, 5 and 7 days) of binary transgenic mice received DT (IT, 10ng), and a fourth cohort of healthy animals served as a control, with timing of DT delivery such that all mice were sacrificed on the same day. Lungs cells were immediately isolated and barcoded to identify individual donor animals, then pooled and subjected to library construction using 10x-Genomics Single Cell 3' RNA sequencing kit v.3. Global plot of all lung cells at all time points using uniform manifold approximation and projection (UMAP) in R revealed 21 distinct populations which could be assigned in to four major groupings: immune; endothelial, stromal and epithelial (B). UMAP plots of global lung cells are shown for each mouse cohort: control (blue); day 3 (green) day 5 (red) and day 7 (purple) (C). A machine learning model was used to predict cells that become more separable during treatment based on their molecular measurements (https://github.com/neurorestore/Augur) (D). 
Figure 4. Endothelial cell populations in control and DT treated binary transgenic DTR mice: UMAP representation of the re-clustered endothelial populations for all cohorts produced 8 distinct EC clusters (A). The UMAP plots for each cohort are shown separately: control (blue); day 3 (green) day 5 (red) and day 7 (purple) The dotted line delineates cluster 1 which was unique in that it consisted of four zones (Z-1 to Z-4) each specific to a single time cohort (B). The numbers of lung ECs in the three cohorts treated with DT (Days 3, 5 and 7) are expressed as fold-change relative to control for all EC populations (Total Cells) in the insert and broken down for EC cluster in the graph. (C). RNA velocity analysis with the magnitude of the velocity vector indicated by the size and length of the arrows (D). Cells from the four different cohorts are shown in blue (Control), green (Day 3), red (Day 5) and purple (Day 7).

Figure 5. aCap and gCap genes in EC populations pre and post injury: Typical aCap ECs genes include: A) Car4 (Carbonic Anhydrase 4); B) Endrb (endothelin receptor type-B); C) Fibin (Fin Bud Initiation Factor Homolog); and D) Tbx2 (T-Box Transcription Factor 2). In contrast, gCap genes include: E) Gpihbpl (Glycosylphosphatidylinositol Anchored High Density Lipoprotein Binding Protein 1); F) Plvap (Plasmalemma Vesicle Associated Protein); G) Cd93; and H) Ptprb (Protein Tyrosine Phosphatase Receptor Type B). Day 3 (green); Day 5 (red) and Day 7 (purple) with cluster 7 enlarged in the insets.

Figure 6. Temporal evolution of expression of angiogenic genes pre and post EC ablation: Apln (Apelin) (A), Kdr (VEGFR2 (B), CD34 (C), Procr (Protein C receptor) (D), Aplnr (Apelin receptor) (E) and Flt1 (VEGFR1) (F); and markers of proliferation: FoxM1 (G) and Ki67 (H). Lung ECs from control mice (blue) are shown on the left and cells from the DT-treated cohorts 
are presented on the right: Day 3 (green); Day 5 (red) and Day 7 (purple) with cluster 7 enlarged in the insets.

Figure 7. Differential gene expression profiles within transitional cluster 1 before and after

EC ablation: Heatmaps of the top 50 differentially expressed genes contrasting zone 1 (Control) to zone 2 (Day 3), zone 2 (Day 3) to zone 3 (Day 5) and zone 3 (Day 5) to zone 4 (day 7).

Expression values correspond to scaled (Z-score) log-transformed transcript counts (A). Volcano plots showing differential gene expression between zones 1 and $2(B)$, zones 2 and $3(\mathrm{C})$ and zones 3 and 4 (D).

Figure 8. Impairment or inhibition of the apelin pathway leads to failure of recovery after

EC ablation: Expression of apelin from a publicly available dataset (31) in young (3 months) versus old (24 months) mice $(*=p<0.05$, unpaired t-test) (A). Apelin expression assessed by qRT-PCR expressed as the difference in the $\mathrm{Ct}$ values for apelin versus GAPDH (delta $\mathrm{Ct}$ ) in young (3 month) vs. old (12 months) Cdhn5-DTR binary transgenic mice $(* *=p<0.01$, unpaired t-test) (B). Survival after IT instillation of DT of either 3 (Young) or 12 month-old (Old) Cdhn5DTR with or without administration of the apelin antagonist, ML221 (10mg/kg IP). Survival of old mice or mice receiving ML221 was significantly different from young control mice $(\mathrm{p}=$ 0.02, Mantel Cox log rank test).

Figure 9. Schematic of EC populations contributing to microvascular repair: At baseline (Day 0), there are two main alveolar groups of capillary ECs: larger apelin positive aCap ECs, termed aerocytes, that play a key structural role in forming the air-blood barrier; and smaller 
apelin receptor (Aplnr) expressing gCap ECs, which are found in the thicker regions at the corners of the alveoli. After DT-induced EC ablation, there is a marked depletion of both EC populations and the appearance of novel transitional and transient populations. At Day 3, there is the appearance of stem-like gCap ECs that paradoxically express apelin, but not its receptor, and are characterized by various stem and progenitor cell markers but show no evidence of proliferation. By Day 5, these transition to ECs expressing Aplnr which have a strong proliferative phenotype, as evidenced by FoxM1 and Ki67 expression, and then rapidly replenish depleted EC pools, including aCap ECs, by Day 7. This transition is orchestrated by the interaction of apelin with its receptor as a critical mechanism in lung microvascular regeneration after EC injury. AT1, alveolar type -1 epithelial cell; AT2, alveolar type-2 epithelial cell; aplnr, apelin receptor; ANGPT2, angipoietin 2; PROCR, protein C receptor. 


\section{Table 1. Top ten differentially expressed genes at baseline (day 0 ) compared with cluster 0 (capillary type-B ECs)}

\begin{tabular}{|c|c|c|c|c|}
\hline & Gene & Full name & Avg logFC & p-val adj \\
\hline \multirow{3}{*}{$\begin{array}{r}\text { Cluster } 1 \\
\text { (zone 1) }\end{array}$} & S100a6 & S100 Calcium Binding Protein A6 & 1.286839 & $2.08 \mathrm{E}-16$ \\
\hline & Emp2 & Epithelial membrane protein 2 & 1.208959 & $1.08 \mathrm{E}-09$ \\
\hline & Sftpc & Surfactant Protein C & 1.103239 & $1.00 \mathrm{E}+00$ \\
\hline \multirow[t]{9}{*}{ Cluster 2} & Emp2 & Epithelial membrane protein 2 & 3.149327 & $0.00 E+00$ \\
\hline & Ednrb & Endothelin Receptor Type B & 2.918765 & $0.00 E+00$ \\
\hline & Igfbp7 & Insulin Like Growth Factor Binding Protein 7 & 2.780079 & $0.00 E+00$ \\
\hline & Fibin & Fin Bud Initiation Factor Homolog & 2.466593 & $0.00 \mathrm{E}+00$ \\
\hline & AW112010 & Small secreted protein interferon-induced & 2.417079 & $0.00 E+00$ \\
\hline & Car4 & Carbonic Anhydrase 4 & 2.277432 & $0.00 \mathrm{E}+00$ \\
\hline & Tbx2 & T-Box Transcription Factor 2 & 2.117743 & $0.00 E+00$ \\
\hline & $\mathrm{Kdr}$ & Kinase Insert Domain Receptor & 1.828296 & $1.05 \mathrm{E}-250$ \\
\hline & Pmp22 & Peripheral Myelin Protein 22 & 1.854179 & $8.18 \mathrm{E}-246$ \\
\hline \multirow[t]{7}{*}{ Cluster 3} & Egr1 & Early Growth Response 1 & 1.906815 & 2.47E-155 \\
\hline & Junb & Fos Proto-Oncogene, AP-1 Transcription Factor Subunit & 1.506061 & 2.73E-121 \\
\hline & Socs3 & Suppressor Of Cytokine Signaling 3 & 1.340062 & 1.99E-101 \\
\hline & Fos & Fos Proto-Oncogene, AP-1 Transcription Factor Subunit & 1.542477 & $4.32 \mathrm{E}-100$ \\
\hline & ler3 & Immediate Early Response 3 & 1.31182 & $1.81 \mathrm{E}-85$ \\
\hline & Fosb & FosB Proto-Oncogene, AP-1 Transcription Factor Subunit & 1.647221 & $2.50 \mathrm{E}-81$ \\
\hline & ler2 & Immediate Early Response 2 & 1.295898 & 4.79E-74 \\
\hline \multirow[t]{10}{*}{ Cluster 6} & Gpx3 & Glutathione Peroxidase 3 & 2.021953 & 3.34E-90 \\
\hline & Aldh1a1 & Aldehyde Dehydrogenase 1 Family Member A1 & 1.787767 & $2.89 E-66$ \\
\hline & Inmt & Indolethylamine N-Methyltransferase & 2.394997 & $1.04 \mathrm{E}-58$ \\
\hline & Mgp & Matrix Gla Protein & 2.458705 & $1.24 \mathrm{E}-58$ \\
\hline & Mfap4 & Microfibril Associated Protein 4 & 1.217247 & $2.18 \mathrm{E}-44$ \\
\hline & Gsn & Gelsolin & 2.119499 & 3.09E-37 \\
\hline & Fth1 & Ferritin Heavy Chain 1 & 1.250302 & $6.86 \mathrm{E}-28$ \\
\hline & Cdo1 & Cysteine Dioxygenase Type 1 & 1.063919 & $2.12 \mathrm{E}-27$ \\
\hline & Ppp1r14a & Protein Phosphatase 1 Regulatory Inhibitor Subunit 14A & 1.104893 & $2.14 \mathrm{E}-24$ \\
\hline & Lgals1 & Galectin 1 & 1.611949 & $3.93 E-23$ \\
\hline \multirow[t]{10}{*}{ Cluster 7} & Top2a & DNA Topoisomerase II Alpha & 2.144883 & $9.68 \mathrm{E}-181$ \\
\hline & Prc1 & Protein Regulator of Cytokinesis 1 & 1.617355 & $6.42 \mathrm{E}-169$ \\
\hline & Rrm2 & Ribonucleotide Reductase Regulatory Subunit M2 & 1.491459 & 4.06E-161 \\
\hline & Pbk & PDZ Binding Kinase & 1.375946 & 1.27E-156 \\
\hline & Mki67 & Marker of Proliferation Ki-67 & 1.785495 & 1.90E-151 \\
\hline & Kif22 & Kinesin Family Member 22 & 1.192686 & $8.32 E-147$ \\
\hline & Birc5 & Baculoviral IAP Repeat Containing 5 (survivin) & 1.737699 & 1.39E-146 \\
\hline & Cenpf & Centromere Protein F & 1.522951 & 1.09E-144 \\
\hline & Mxd3 & MAX Dimerization Protein 3 & 1.066775 & 3.79E-143 \\
\hline & Cdca8 & Cell Division Cycle Associated 8 & 1.363606 & $5.34 \mathrm{E}-142$ \\
\hline
\end{tabular}


bioRxiv preprint doi: https://doi.org/10.1101/2021.07.12.452061; this version posted July 12,2021 . The copyright holder for this preprint (which

was not certified by peer review) is the author/funder, who has granted bioRxiv a license to display the preprint in perpetuity. It is made available under aCC-BY-NC-ND 4.0 International license.
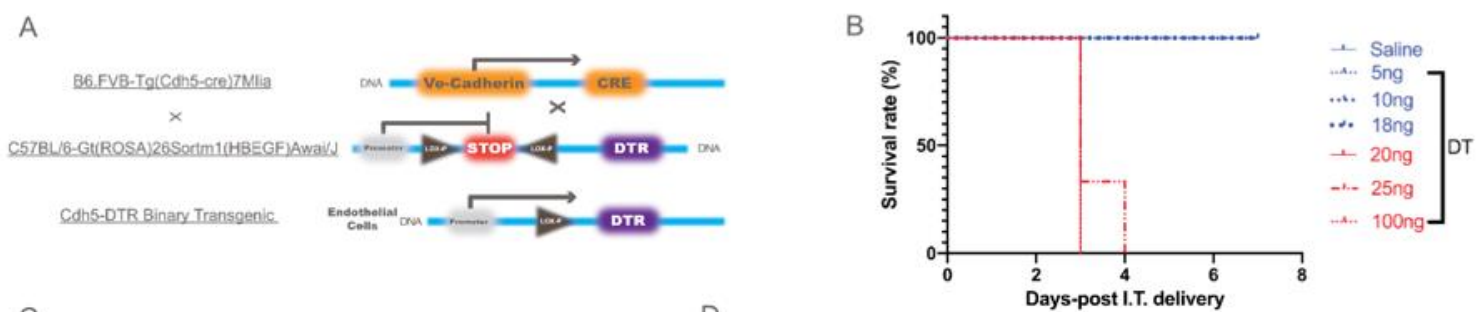

C

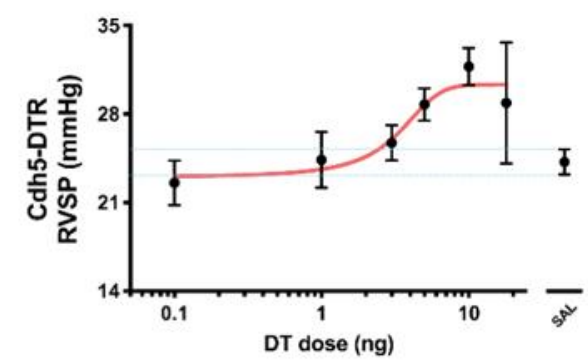

$E$

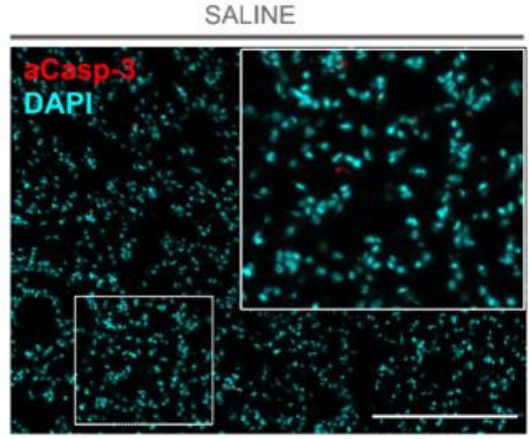

F

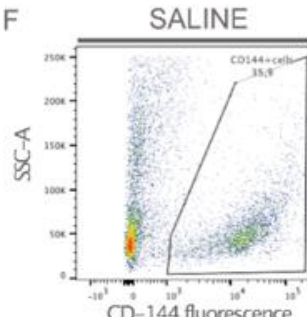

- 44 fluorescence

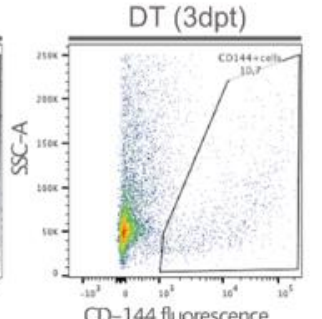

CD-144 fluorescence

DT-samples

SAL-samples
D

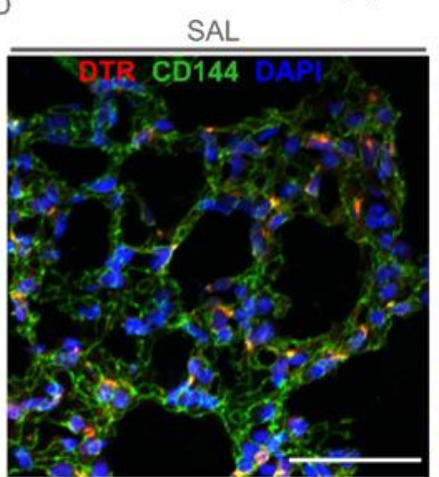

Day 3

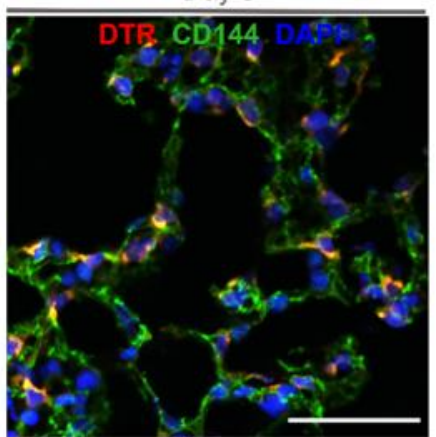

Day 3

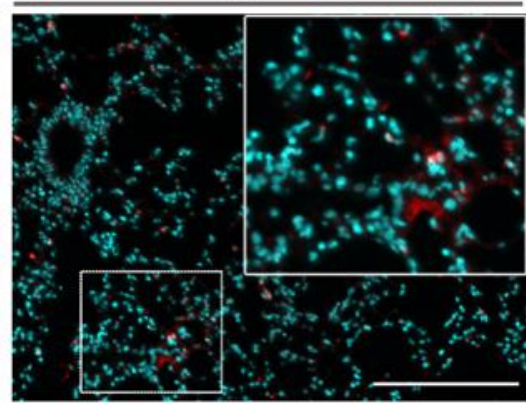

Day 7

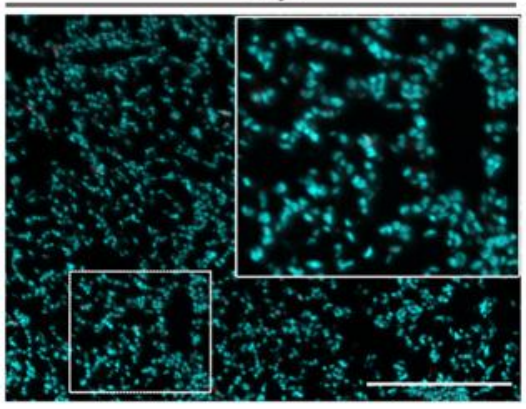

G

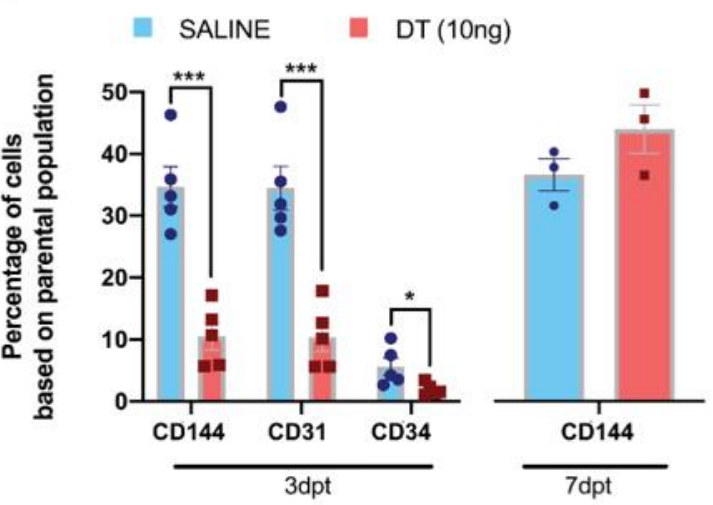

Figure 1 


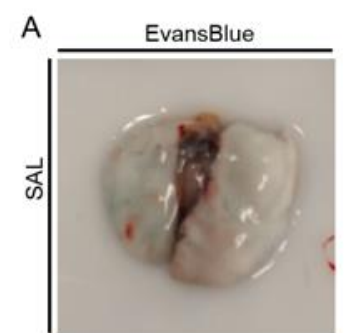

B

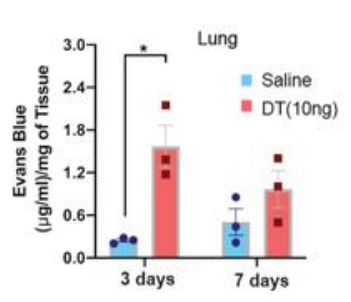

C
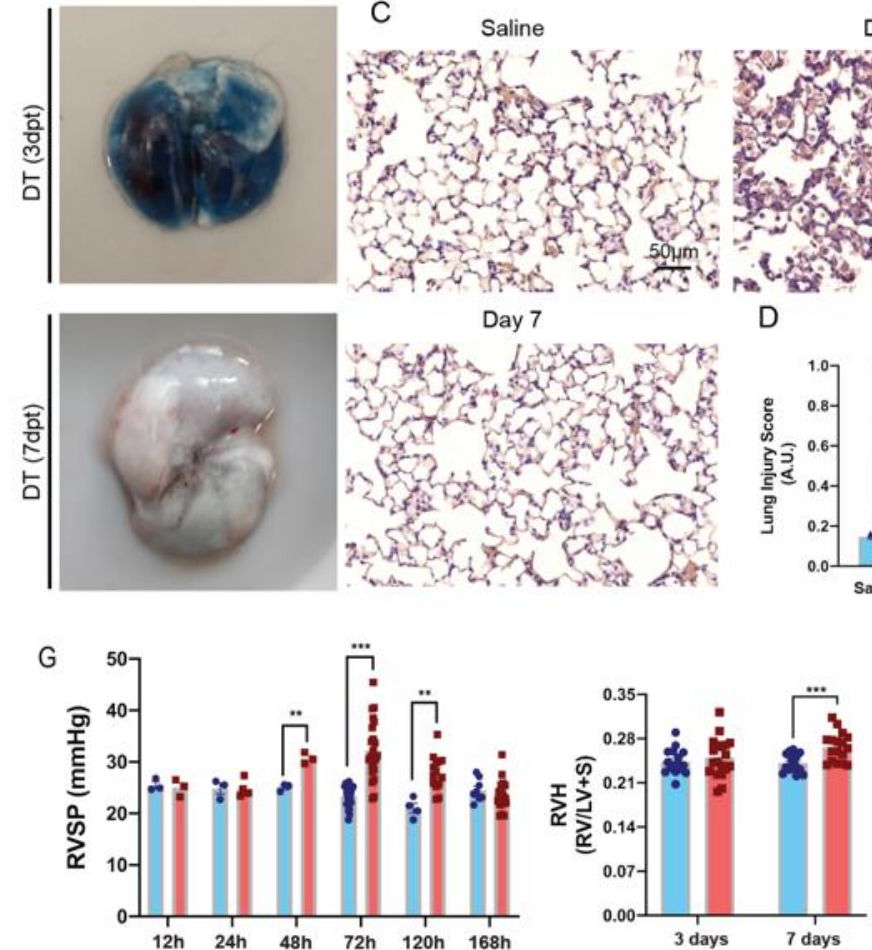

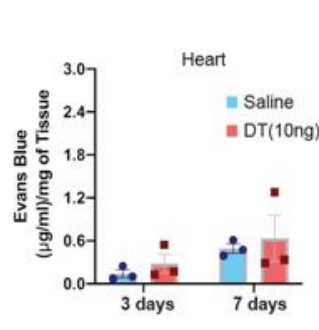

Day 3

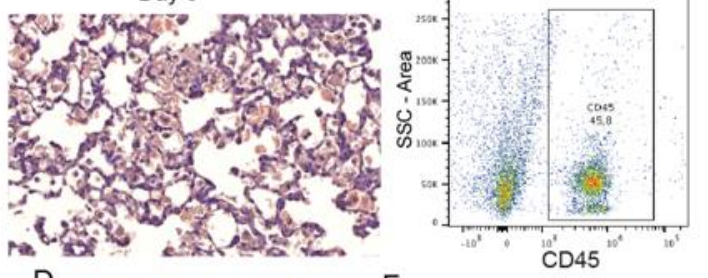

Saline

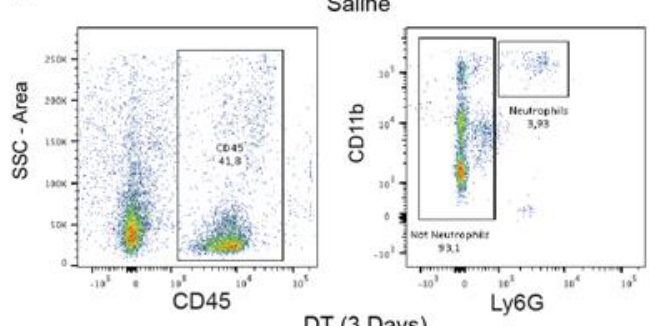

DT (3 Days)
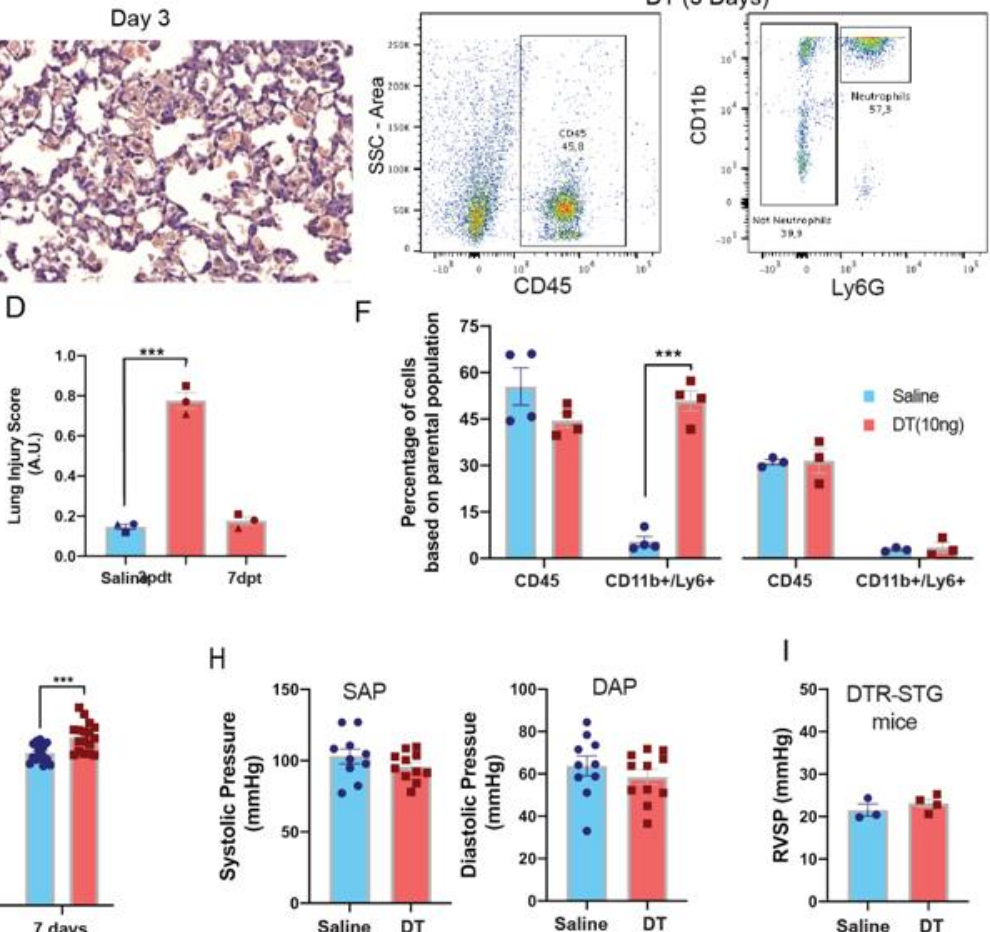

${ }^{50} 7$ DTR-STG

Saline DT

Figure 2 
bioRxiv preprint doi: https://doi.org/10.1101/2021.07.12.452061; this version posted July 12,2021 . The copyright holder for this preprint (which was not certified by peer review) is the author/funder, who has granted bioRxiv a license to display the preprint in perpetuity. It is made available under aCC-BY-NC-ND 4.0 International license.

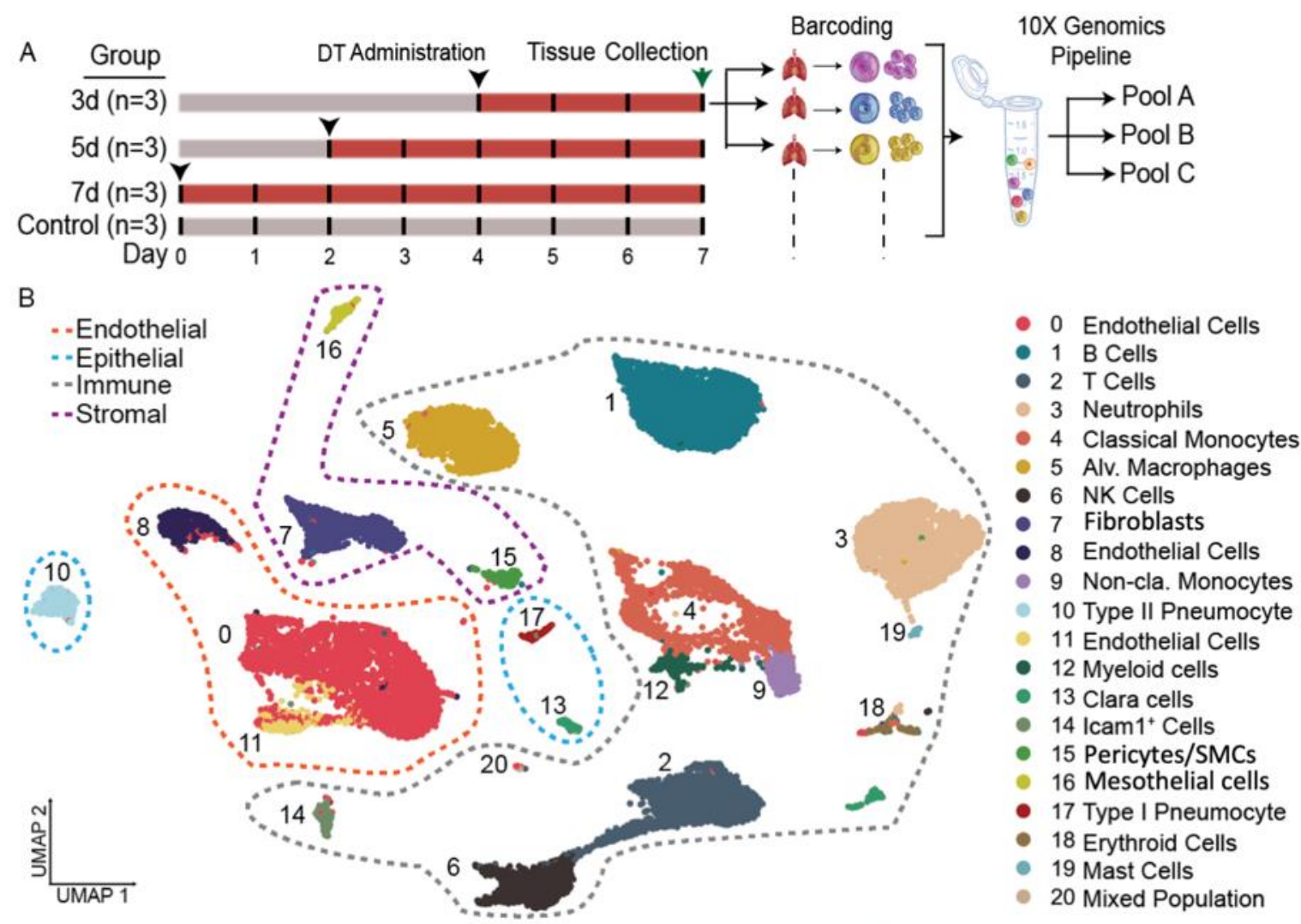

C
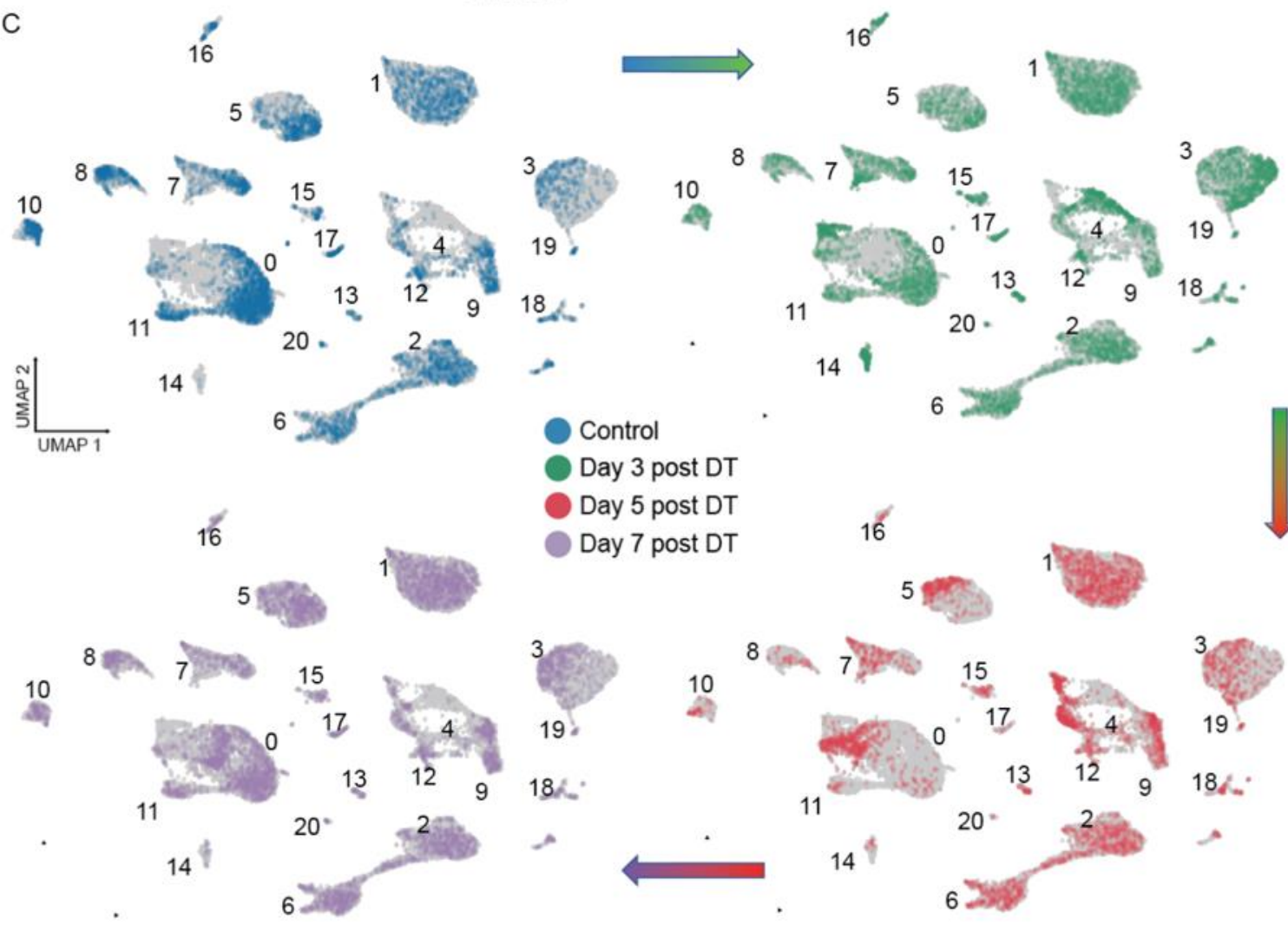

141
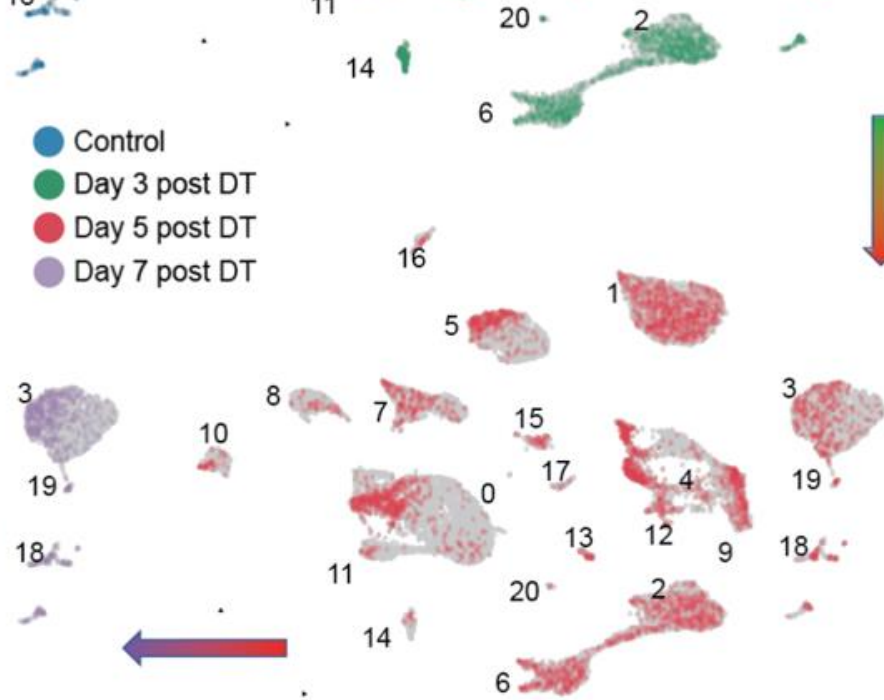

D

Figure 3

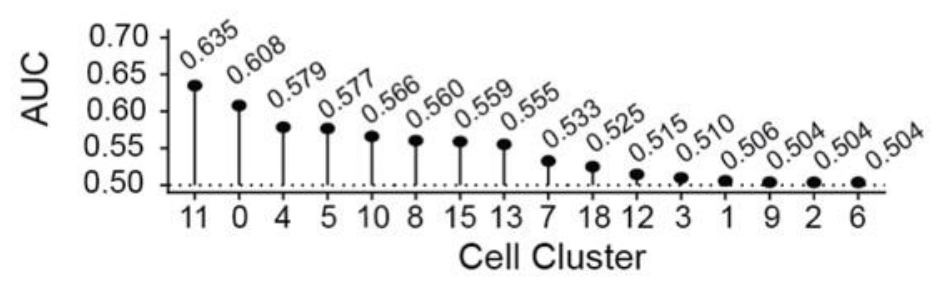


bioRxiv preprint doi: https://doi.org/10.1101/2021.07.12.452061; this version posted July 12,2021 . The copyright holder for this preprint (which was not certified by peer review) is the author/funder, who has granted bioRxiv a license to display the preprint in perpetuity. It is made available under aCC-BY-NC-ND 4.0 International license.

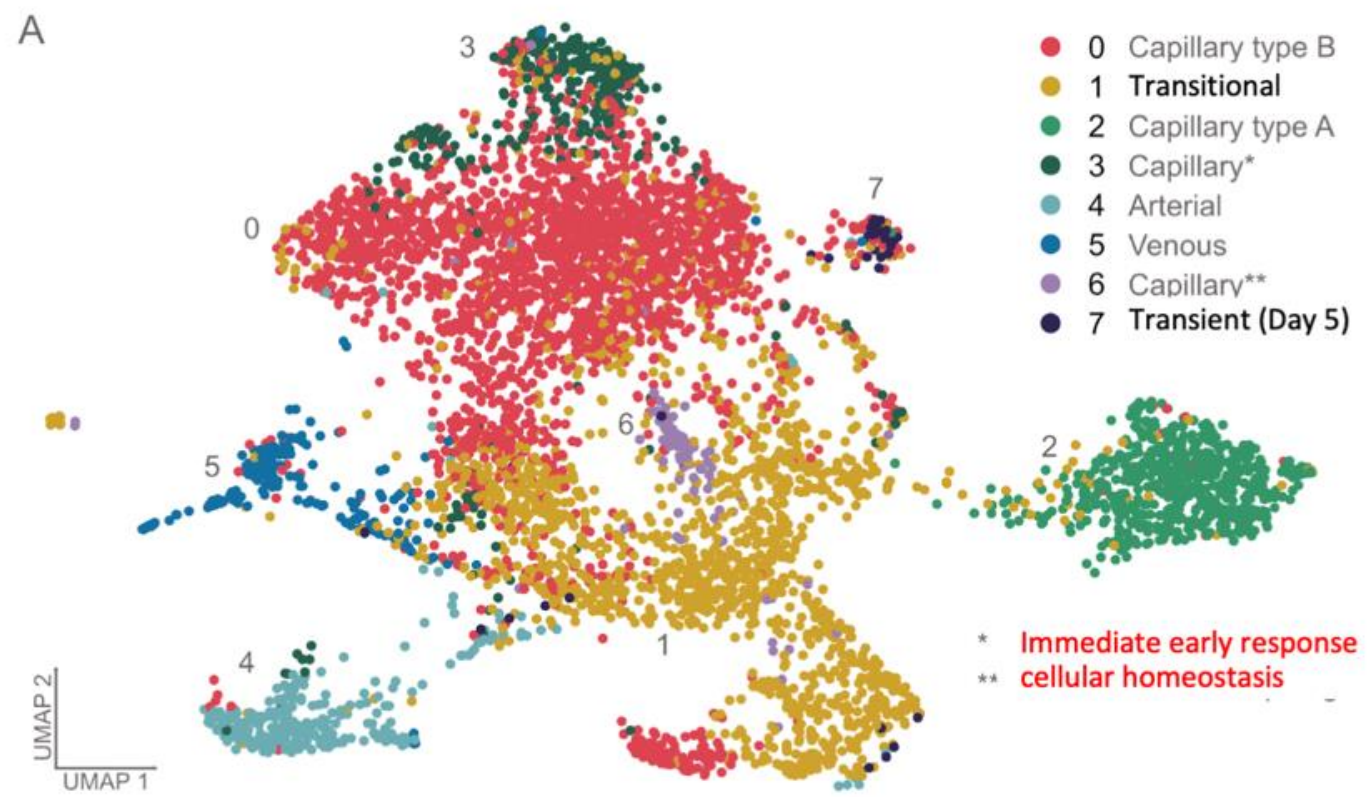

$\mathrm{B}$

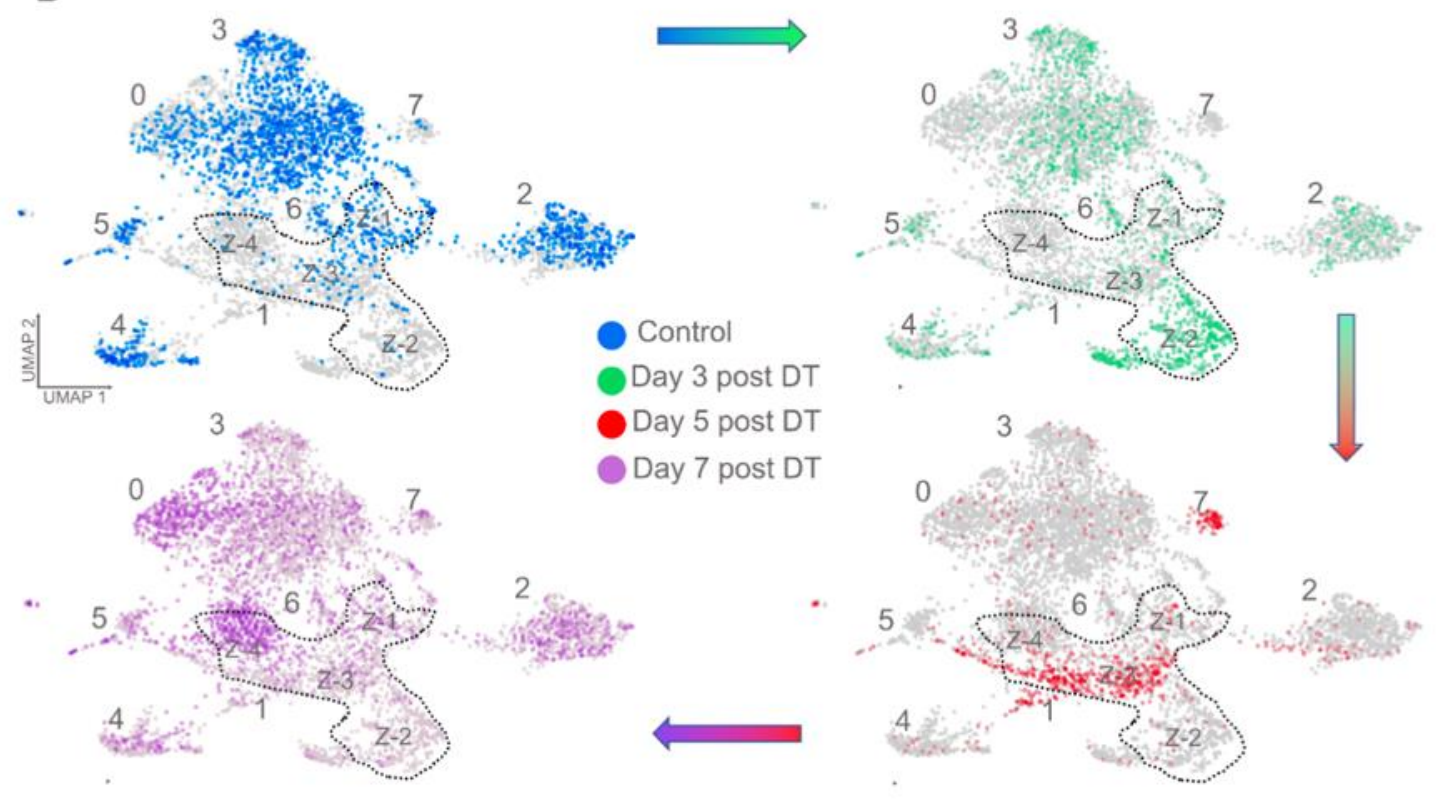

C
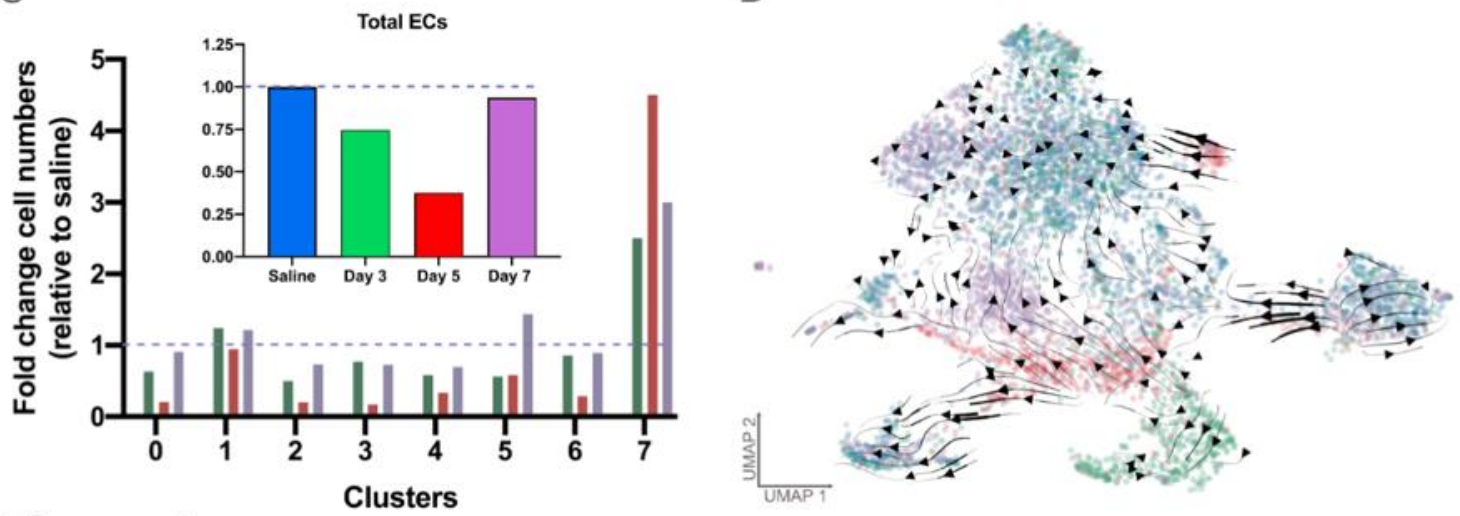

Figure 4 


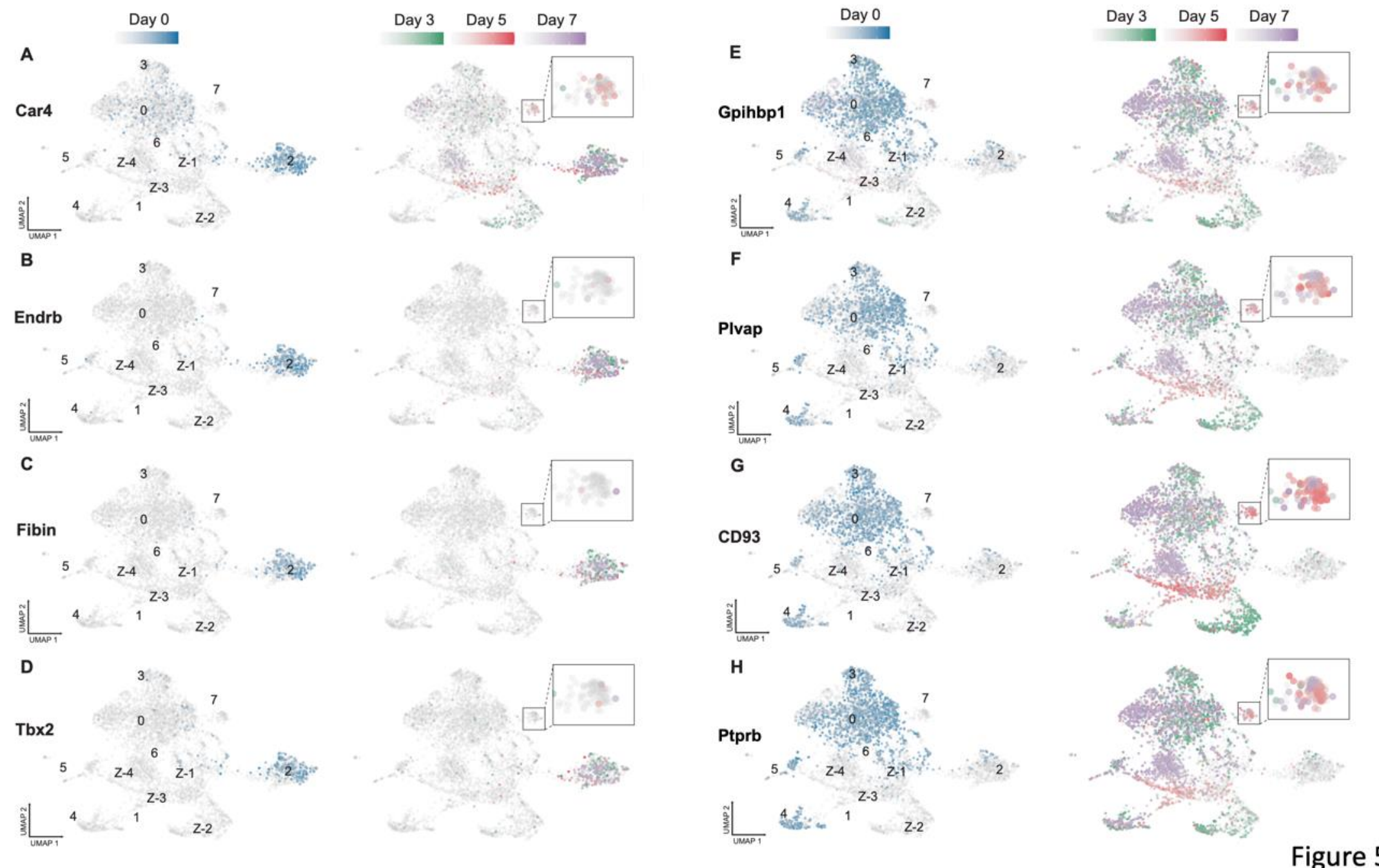

Figure 5 

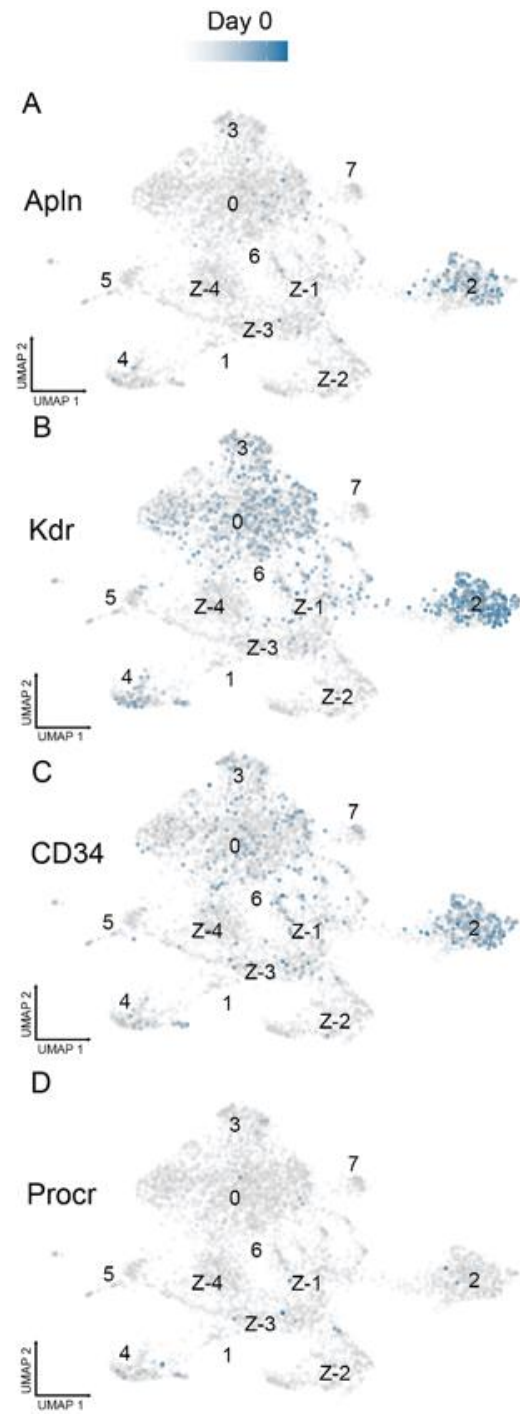

2 $\begin{array}{lll}\text { Day } 3 & \text { Day } 5 & \text { Day } 7\end{array}$
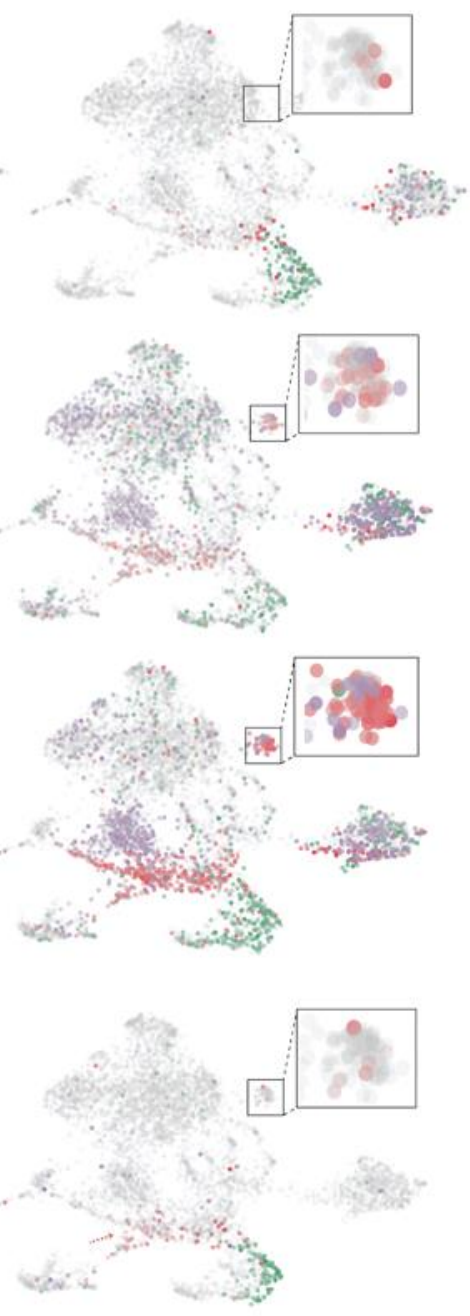

E
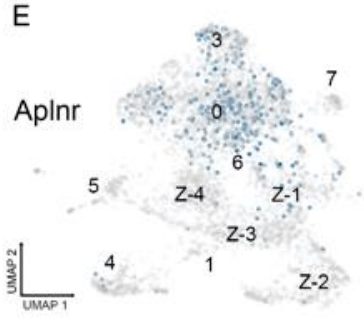

$\mathrm{F}$

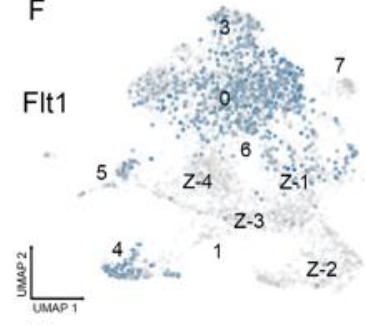

G

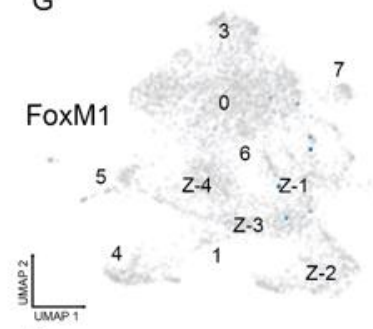

$\mathrm{H}$

Ki67

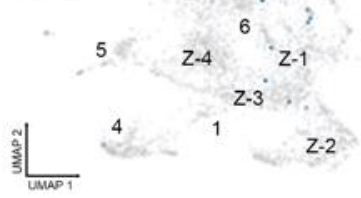

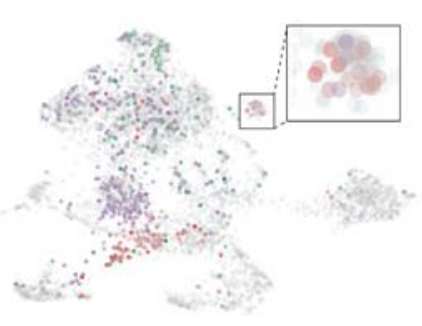

$\begin{array}{lll}\text { Day } 3 & \text { Day } 5 & \text { Day } 7\end{array}$
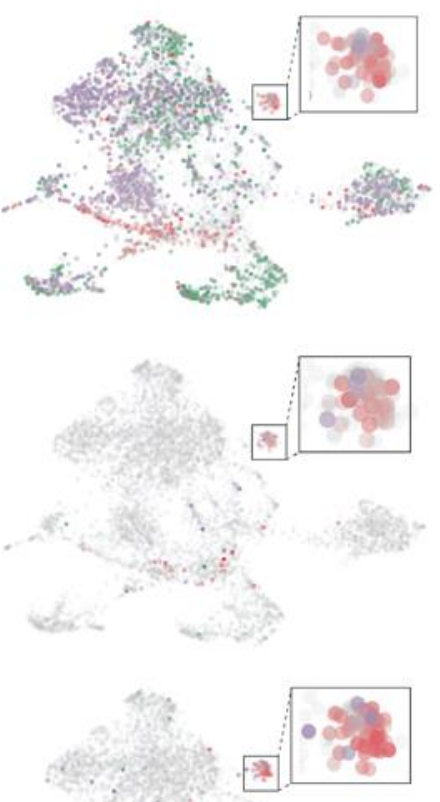

Figure 6

30 
bioRxiv preprint doi: https://doi.org/10.1101/2021.07.12.452061; this version posted July 12, 2021. The copyright holder for this preprint (which was not certified by peer review) is the author/funder, who has granted bioRxiv a license to display the preprint in perpetuity. It is made available under aCC-BY-NC-ND 4.0 International license.

A
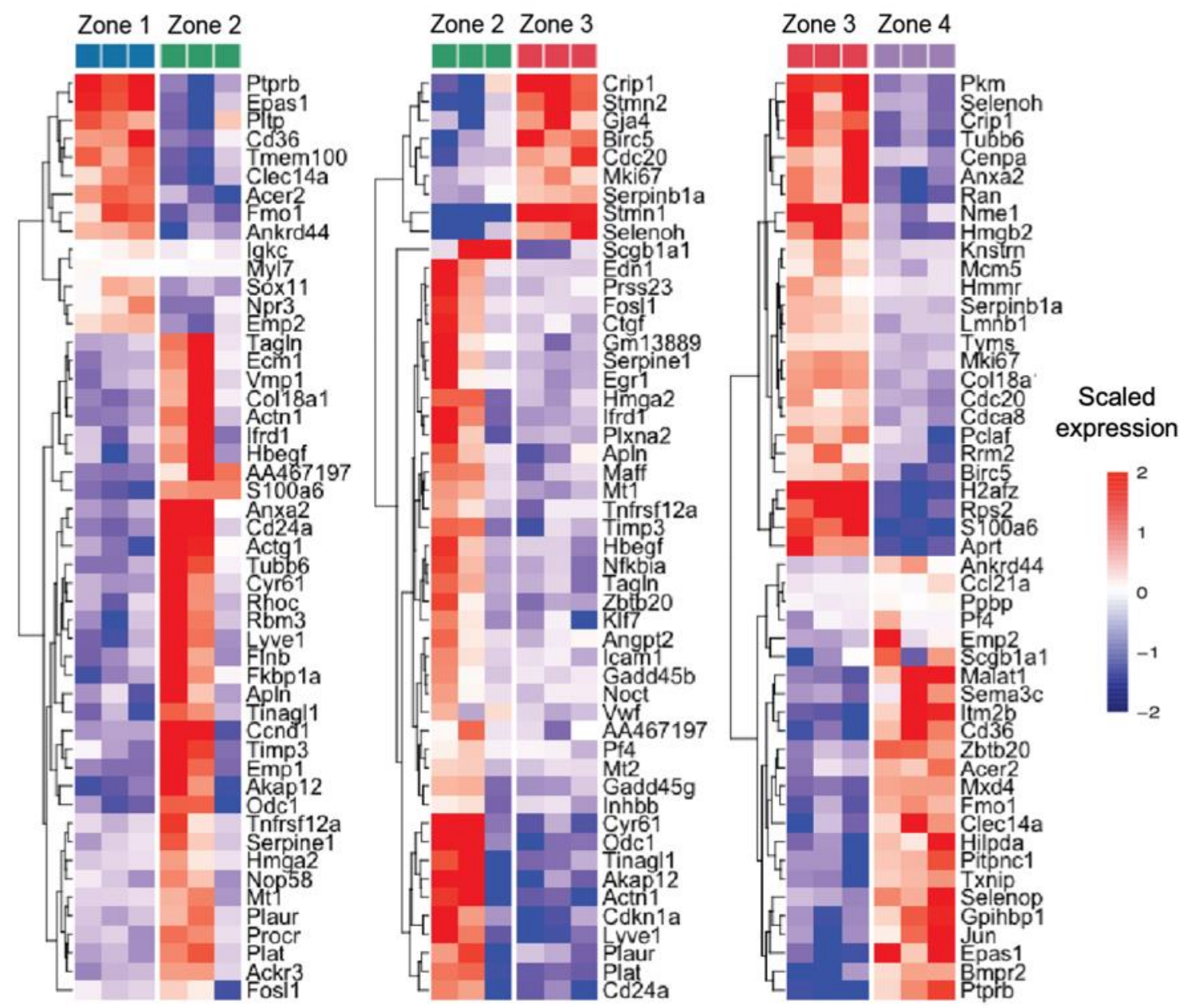

B

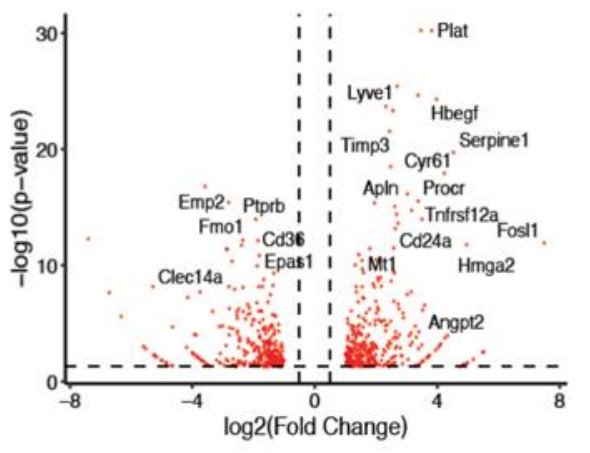

C

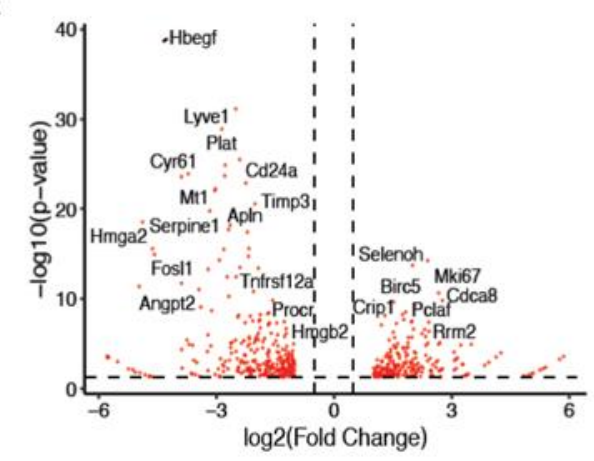

D

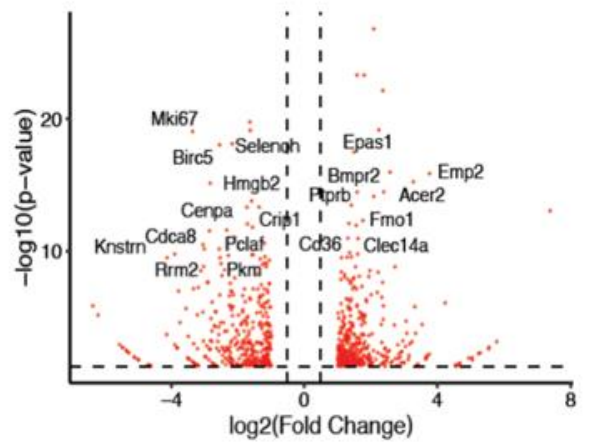

Figure 7 
A

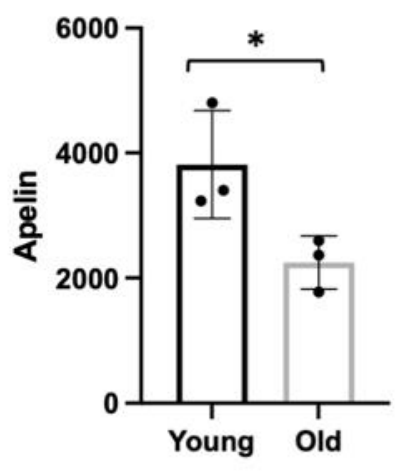

B

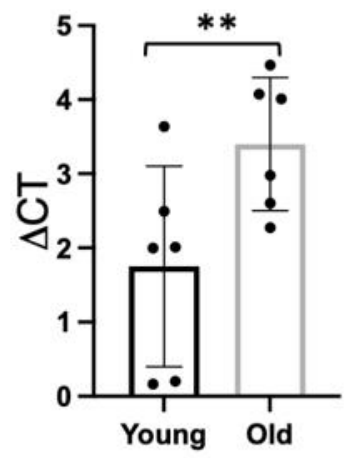

C
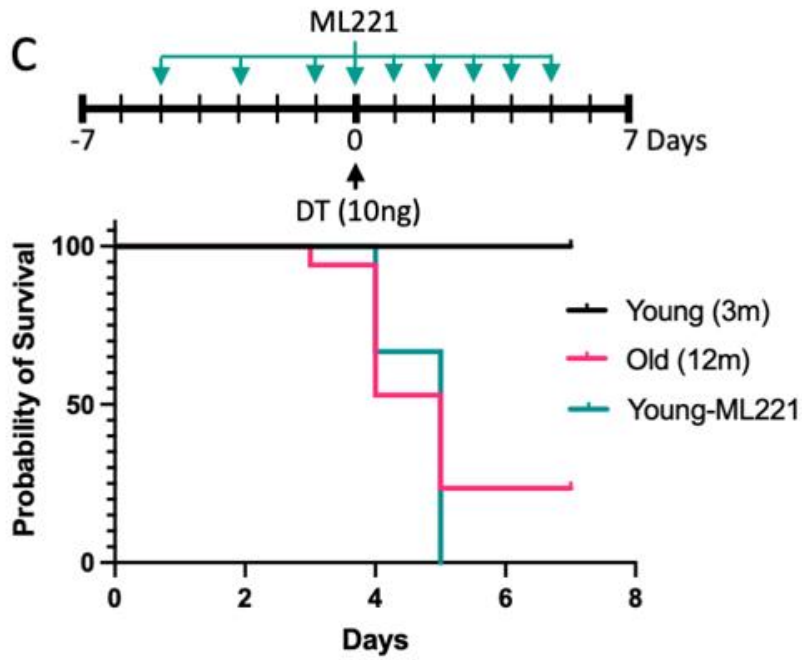

Figure 8 
bioRxiv preprint doi: https://doi.org/10.1101/2021.07.12.452061; this version posted July 12, 2021. The copyright holder for this preprint (which was not certified by peer review) is the author/funder, who has granted bioRxiv a license to display the preprint in perpetuity. It is made available under aCC-BY-NC-ND 4.0 International license.

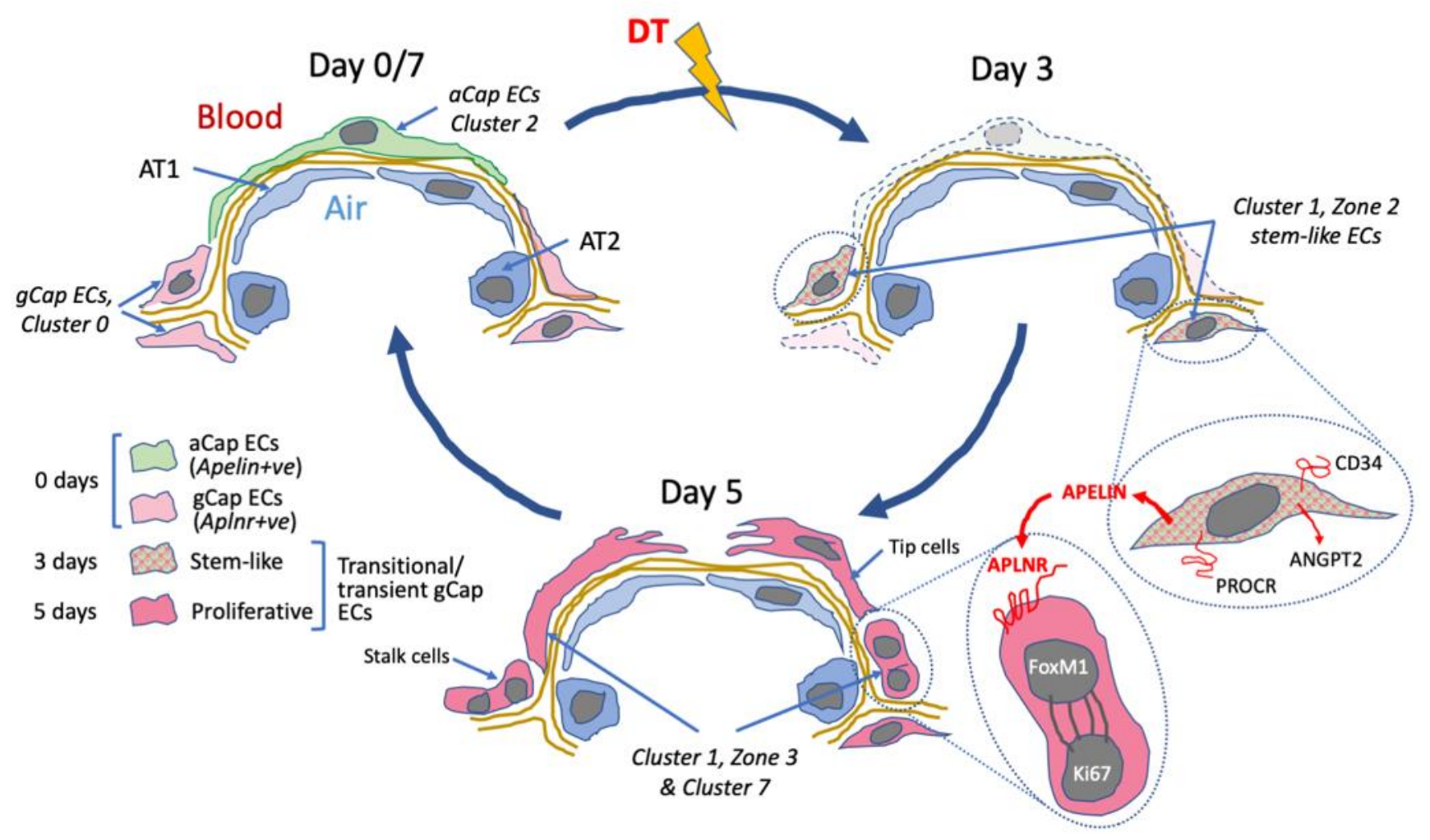

Figure 9 